\title{
LA TRANSFORMACIÓN MATERIAL E IDEOLÓGICA DE UNA CIUDAD DE HISPANIA: ILURO (MATARÓ) ENTRE LOS SIGLOS I Y VII D.C.
}

\author{
POR \\ VÍCTOR REVILLA \\ Departament de Prehistòria, Història Antiga i Arqueologia. Universitat de Barcelona \\ XABIER CELA \\ Àrea d'Intervenció Arqueològica. Museu de Mataró
}

\begin{abstract}
RESUMEN
El gran número de excavaciones arqueológicas realizadas en el núcleo histórico de Mataró (provincia de Barcelona) en las dos últimas décadas ha alterado radicalmente el conocimiento de la ciudad romana de Iluro y permite reconstruir los rasgos generales de su evolución material e institucional, desde el municipium imperial hasta una nueva forma de hábitat que caracteriza los siglos VI y VII. Este proceso aporta algunos elementos de debate para entender la evolución de la vida urbana en el contexto de las transformaciones generales del mundo tardoantiguo, así como la variedad de situaciones resultantes.
\end{abstract}

\section{SUMMARY}

As a result of the several archaeological works carried out in the Roman town Iluro (Barcelona) in the last two decades the knowledge on the town has undergone a radical change. Now, this information allows us to reconstruct the main features: its material and institutional evolution from the imperial municipium to the new type of habitat characteristic of the VI and VII centuries AD. This process contributes with some arguments to the debate for the understanding on the evolution of the urban life in the context of the general changes in late antiquity, as well as the different situations created as its result.

PALABRAS CLAVE: Urbanismo romano, cerámica romana, Antigüedad tardía.

KEY WORDS: Roman urbanism, Roman pottery, late antiquity.

\section{PARVA OPPIDA Y TRANSFORMACIÓN DE LA VIDA URBANA AL FINAL DE LA ANTIGÜE- DAD: EL CASO DE ILURO}

Iluro es una de las ciudades fundadas en el contexto de la reorganización territorial y administrativa de las sociedades indígenas del litoral catalán impulsada por Roma entre finales del siglo II e inicios del I a.C. (fig. 1). Como en otros casos cercanos (Baetulo, Blandae), la elección del lugar muestra una voluntad de segregación y control con respecto al poblamiento ibérico anterior; en este caso, el poblado de Burriac, que había articulado política y socialmente el territorio de la comarca del Maresme entre mediados del siglo IV y finales del II a.C. ${ }^{1}$

Existe constancia de la plena naturaleza urbana de Iluro en época imperial. Una cita de Plinio el Viejo la define como oppidum civium Romanorum (NH 3.4.22) y autores como Pomponio Mela (2.5.90) o Claudio Ptolomeo (2.6.18) también la mencionan como ciudad, situándola con cierta precisión en relación con otras poblaciones del litoral de Cataluña. Esta información es corroborada por un corpus epigráfico ${ }^{2}$ que muestra algunos aspectos de la vida local e, indirectamente, sus instituciones. Su existencia indica la existencia de una comunidad cívica, pero es difícil precisar su condición jurídica exacta, su funcionamiento y su evolución. Los problemas son aún más importantes en el caso de otras ciudades del litoral de Cataluña, entre Emporiae y Tarraco, mencionadas por los escritores de los siglos I-II d.C. ${ }^{3}$

La arqueología permite definir con cierta aproximación algunos de los rasgos de la comunidad que aparece representada en las inscripciones. Al mismo tiempo, las evidencias relacionadas con la organización del espacio, la economía, la vida social y la religión, así como la evolución general del hábitat muestran, más allá de los ideales y las imágenes elaboradas por la ideología, el alcance real del fenómeno urbano. Las intervenciones realizadas en el centro histórico de Mataró

1 El abandono se sitúa en un momento avanzado del siglo I, cuando Iluro parece haberse consolidado como nuevo centro del territorio: García Roselló, Martín, Cela, 2002; cf. Olesti, 1995.

Inscriptions Romaines de Catalogne; en adelante, IRC, volúmenes I y $\mathrm{V}$.

3 Estado de la cuestión sobre la urbanización de la zona en Guitart, 1993; Rodà, 1989. 

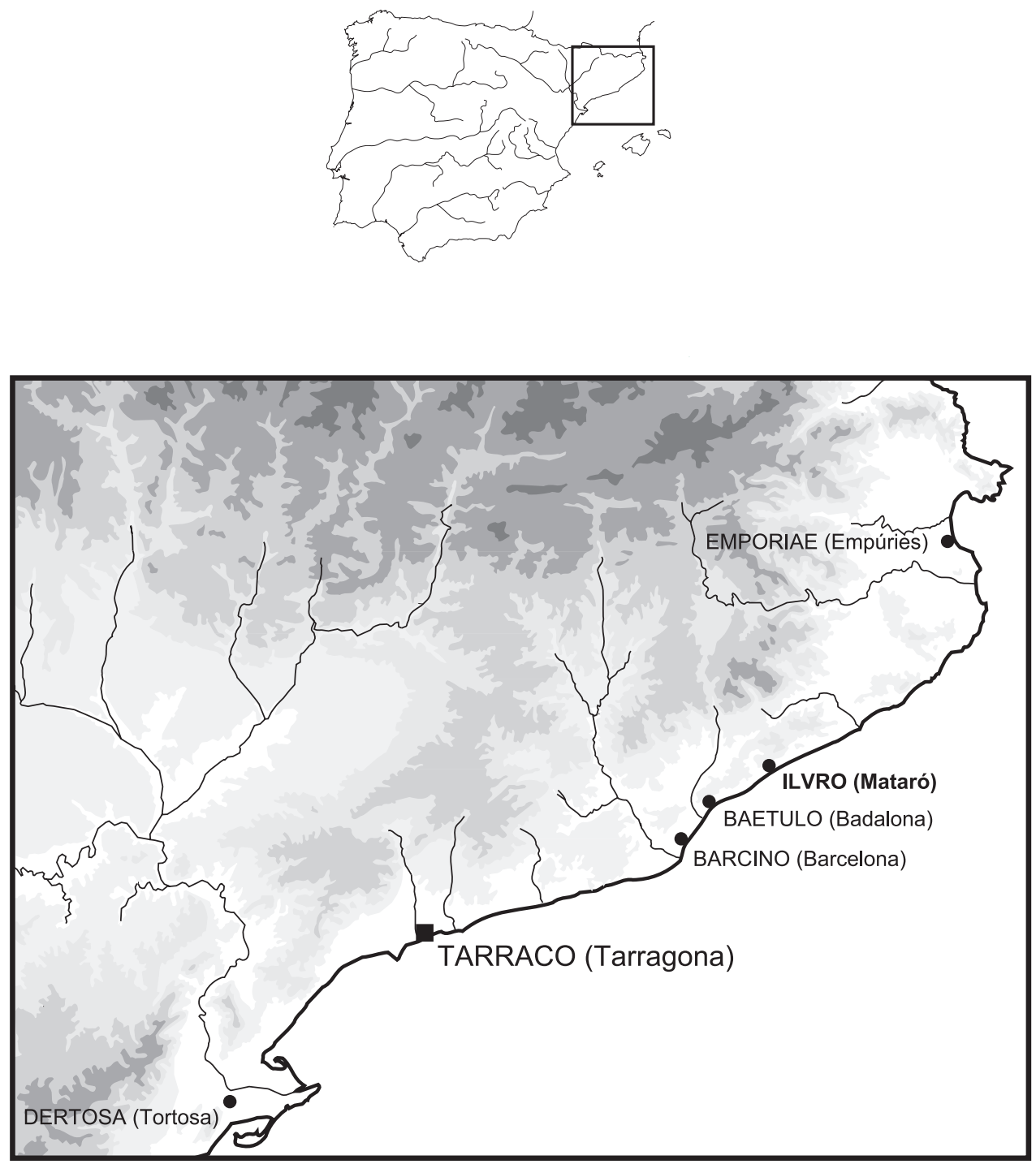

Figura 1. Situación de la ciudad de Iluro.

en las dos últimas décadas, que han permitido revisar los datos recogidos entre los siglos XIX y XX, han proporcionado un conocimiento profundo de la ciudad romana ${ }^{4}$. En la actualidad, se dispone de datos sólidos sobre las características del primer núcleo, el urbanismo de época imperial y su evolución hasta los siglos IV-V, las relaciones entre organización del espacio, vida cívica y economía, y, finalmente, sobre la arquitectura privada, algunas de las infraestructuras y los edificios y espacios públicos ligados a la vida administrativa, la religión o el ocio.

\footnotetext{
${ }^{4}$ Cerdà et al., 1997; Cela, Revilla, 2004.
}

La evolución de Iluro durante el periodo imperial muestra coincidencias significativas con otros oppida $c$. $R$. del litoral de Cataluña conocidos arqueológicamente (caso de Baetulo). Estas coincidencias también se aprecian en la transformación de las formas de hábitat hacia nuevas pautas entre los siglos V y VI; una transformación que se produce en un contexto de cambio cultural global. El análisis del proceso seguido por la ciudad de Iluro, por lo tanto, puede aportar elementos de comparación para un mejor conocimiento de la evolución de otras pequeñas ciudades romanas de la Península Ibérica, que presentan una dinámica diferente a la de, por ejemplo, las capitales de provincia o conventus; o de modo más general, respecto a aquellas ciudades hispa- 
nas que durante la antigüedad tardía y en el contexto de la reorganización política y cultural de la Península mantienen alguna importancia como centro de poder ${ }^{5}$.

Es innecesario recordar que la urbanización de la Península Ibérica es un proceso complejo por su desarrollo y formas, y que un gran número de comunidades mencionadas por los autores clásicos se caracterizaba por unas dimensiones y unas capacidades materiales muy modestas. La diversidad de condiciones originarias de un territorio o región incidió en la historia posterior de los núcleos urbanos fundados o reorganizados durante la república y el principado. En este sentido, parece más adecuado conceptualizar y analizar la evolución de la urbanización en Hispania y la situación al final de la Antigüedad, en una perspectiva plural, como resultado de vías y de ritmos diferentes de desarrollo y no como una decadencia lineal e inexorable que habría conducido a la extinción de la vida urbana en el contexto de un proceso de general agotamiento cultural. El caso de Iluro permite plantear la cuestión del dinamismo que caracteriza los procesos internos de estas pequeñas ciudades, que no pueden considerarse simplemente como creaciones artificiales abocadas finalmente a la decadencia.

\section{OPPIDUM CIVIUM ROMANORUM: EVOLU- CIÓN URBANÍSTICA Y SOCIAL DE UNA COMUNIDAD CÍVICA}

Iluro experimentó continuas transformaciones urbanísticas y arquitectónicas entre su fundación y la antigüedad tardía. Estas transformaciones, claramente perceptibles en el registro arqueológico hasta finales del siglo IV o inicios del V d.C., se deben valorar como expresión directa del dinamismo y capacidad de renovación de una comunidad cívica. La situación es menos definida a partir de mediado el siglo V. La desaparición del urbanismo original, el cambio de uso de algunos sectores de la ciudad y la presencia de un conjunto de vertederos relacionados con la vida doméstica indican la existencia de un nuevo tipo de hábitat en los siglos VI y VII, pero las evidencias documentales son limitadas y es difícil reconstruir los factores que caracterizan las nuevas condiciones de vida y, sobre todo, definir el significado de los cambios.

Iluro se funda ex novo en el primer tercio del siglo I a.C. (fig. 2). El núcleo inicial, con una extensión de 7 a

5 Para la ciudad en la Hispania tardía: García Moreno, 1977-78; Barral, 1982; Gutierrez, 1993 y 1996; Giralt, Tuset, 1993; Fuentes, 1999; Gurt, 1999 y 2000-2001; Díaz, 2000; la forma y función de la ciudad tardía son analizadas en varias obras colectivas: Brogiolo, Ward-Perkins, 1999; Brogiolo, Gauthier, Christie, 2000
8 ha se organizaba a partir de una retícula ortogonal definida por el cruce de dos vías principales, cardo y decumanus maximi, y de un conjunto de cardines y decumani minores. El primer urbanismo parece distinguir claramente diversos sectores, una distinción que se mantuvo con pocos cambios hasta los siglos IV-V d.C.: el sector sur del cardo maximus, ocupado por tabernae y un posible macellum, se destinó a actividades comerciales y artesanales; la zona central y oriental, a residencia privada (aquí se concentran algunas domus y evidencias de un hábitat más modesto); la zona norte, más elevada, parece constituir el centro de la vida pública, administrativa y religiosa. Hay que señalar, con todo, que las evidencias relacionadas con esta primera época son muy escasas ${ }^{6}$. El urbanismo y la distribución espacial de las diversas actividades se adaptan y utilizan las condiciones impuestas por la topografía.

Excavaciones recientes han permitido localizar parte del trazado de la muralla, que podría datarse igualmente en época fundacional ${ }^{7}$. El hallazgo confirmaría la referencia a la construcción o reforma de un murum que contiene una inscripción recogida en el siglo XVII y actualmente perdida ${ }^{8}$. Por el contrario, la ciudad parece carecer de ciertas infraestructuras en su fase inicial. Las alcantarillas de algunos cardines minores, por ejemplo, se incorporan en un momento inmediatamente posterior -mediados del siglo I a.C.- en relación con una modificación de la anchura de algunas vías.

A pesar de los progresos en el conocimiento arqueológico de la ciudad, subsisten algunos problemas en relación con las características de la trama ortogonal y con la evolución de la ocupación. En lo que respecta a la primera cuestión, la distribución de algunos cardines y decumani llevó, en un primer momento, a proponer la hipótesis de un único módulo de planta cuadrada y $35 \mathrm{~m}$. de anchura, que parece bastante bien definido en la zona próxima al cruce entre cardo y decumanus maximus ${ }^{9}$. Sin embargo, excavaciones recientes en el sector oriental de Iluro han permitido localizar cardines que no respetan esta modulación ${ }^{10}$. Estos problemas se advierten en otros espacios periféricos, si bien en relación a la presencia de construcciones posteriores. Esta situación sugiere la existencia de insulae de diverso tamaño, que podrían res-

\footnotetext{
6 Reconstrucción del urbanismo en Cerdà et al., 1997, vol. I: 256ss.; novedades en Cela, García Roselló, Pera, 2003; planteamientos diversos sobre la fundación en: Gusi, 1976; Clariana, 1994a-b; Arxé et al. 1986; Olesti, 1995: 331ss.

7 Cela, García Roselló, Pera, 2003: 24-25.

8 IRC I, núm. 104; propuestas sobre el trazado y dimensiones del recinto en: Ribas, 1952: 91; id., 1988²: 118-120; id., 1981; Cerdà et al., 1997, vol. I: 263.

9 Cerdà et al., vol. I, 1997: 261.

${ }^{10}$ Cela, García Roselló, Pera, 2003: 23.
} 


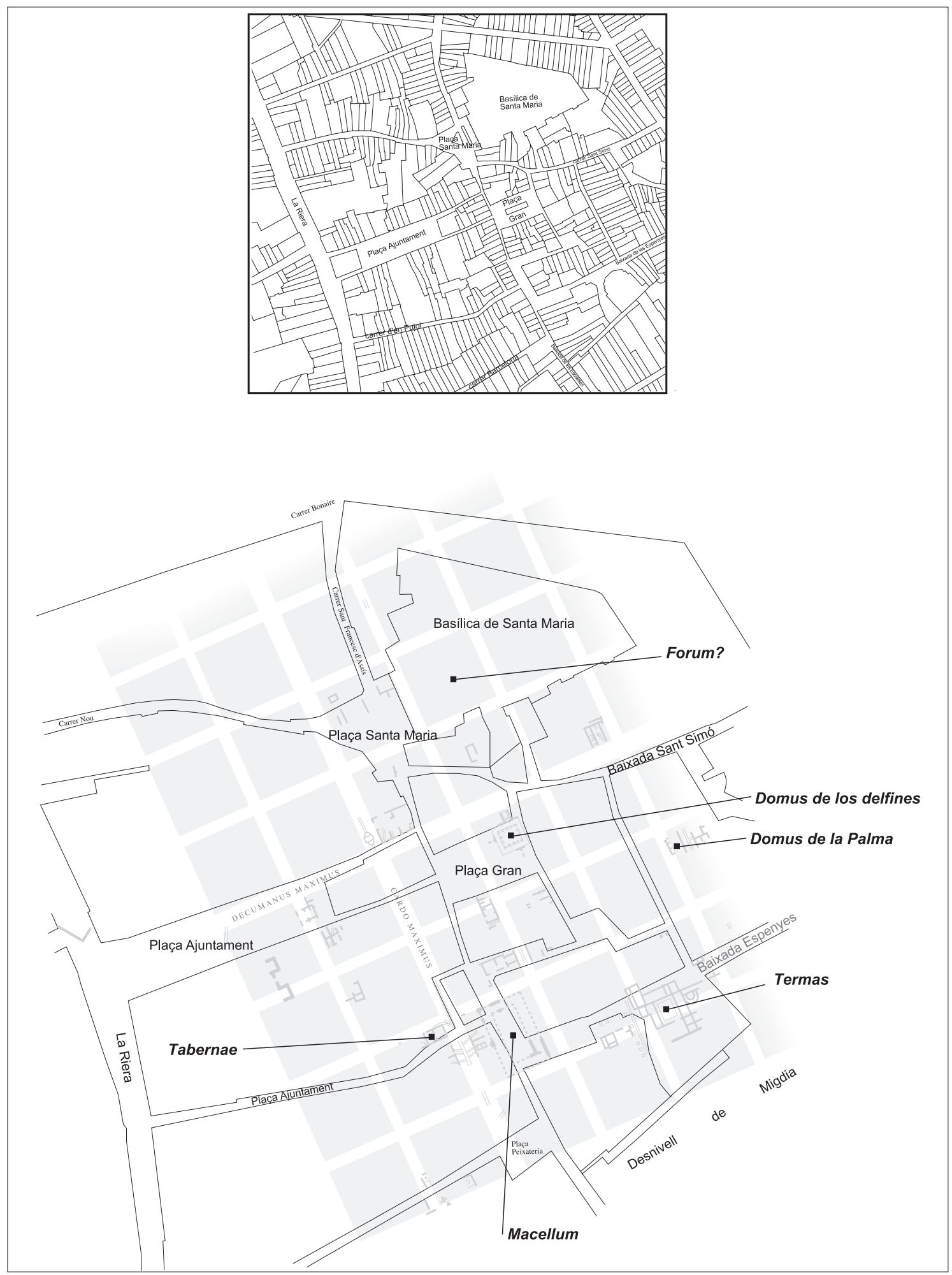

Figura 2. Parcelario del centro histórico de Mataró (arriba). Situación de los sectores conocidos de Iluro y restitución hipotética de la trama urbana (sobre la base de Cerdá et alii, 1997 actualizado en Cela; García; Pera, 2003). 
ponder a otros módulos, o un uso diverso del espacio para solucionar los problemas derivados de encajar la estructura urbana en el emplazamiento escogido ${ }^{11}$. De hecho, se ignora casi por completo cómo se organizó la periferia. Algunas evidencias hacen pensar que los sectores norte y oeste presentarían una menor ocupación respecto a la zona próxima al cruce entre cardo y decumanus maximi; es posible, incluso, que algunos lugares permanecieran desocupados hasta un momento avanzado (s. I-II d.C.). Dado que la trama viaria responde a época fundacional -y parece lógico pensar que se organizó toda la superficie de la ciudad en un mismo momento-, esta situación sugiere que la creación del asentamiento preveía futuras necesidades de crecimiento.

El área periurbana, separada de la ciudad por torrentes, fue ocupada parcialmente por enterramientos; en especial, el sector que correspondería al final del decumanus maximus y la salida suroeste de la ciudad, donde la calle se prolongaría como via exterior ${ }^{12}$. No se puede precisar el momento en que se inicia esta ocupación funeraria, ni la organización y evolución del espacio o espacios cementeriales. De esta zona procede la conocida inscripción IRC I, núm. 101 datada en el siglo I d.C. Las últimas excavaciones han aportado nuevas evidencias de uso desde el siglo II d.C. hasta un momento indeterminado que se situaría entre los siglos IV y V.

Hacia finales del siglo I a.C.-inicios del I d.C. se producen algunas actuaciones arquitectónicas importantes, públicas y privadas, que afectan a toda la ciudad. En este conjunto de actuaciones, destacan, en primer lugar, algunas construcciones monumentales de las que existe constancia arqueológica o epigráfica y que responden claramente a las necesidades materiales e ideológicas de una comunidad cívica. Especialmente importantes son las inscripciones relacionadas con la sistematización de un espacio público y sus edificios: IRC I, núm. 214, que menciona un [-FO]RVM o [-HYPAET]RVM, quizá dedicado por [SEVIRI] AVGVST(ales), e IRC I, núm. 216, que conserva parte de una fórmula relacionada con la construcción o reconstrucción de un monumento. La cronología de ambas se situa en el primer tercio o la primera mitad del siglo I d.C. Otro texto menciona un posible [BALINEUM PVB]LICVM (IRC I, núm. 215). La inscripción incluye además la mención ILVRONENS(ium), que confirma la existencia y actuación consciente de un ordo local en época augustea o durante la primera mitad del siglo I d.C. Tanto estas inscripciones como algunas dedicatorias a divinidades realizadas por seviri augustales, proceden de

\footnotetext{
${ }^{11}$ Situación similar en Baetulo: Guitart, 1976: 231ss.; Padrós 1985a: 88.

${ }^{12}$ Pellicer, 1887: 253-254; Bonamusa, 1972; SAMM 1977: 25-27; Ribas, 1952: 88; id. 1975: 70-71; id. 1988²: 132ss.; Cerdà et al., 1997, vol. I: 263; Jiménez, 1996.
}

la zona de la actual Basílica de Santa María, que ocupa el punto más elevado de la ciudad romana y que fue ocupado posteriormente por un campo de silos y un cementerio cristiano. La concentración de epigrafía pública y la posterior reutilización funeraria sugieren que aquí se localizaba la vida administrativa y religiosa de la ciudad ${ }^{13}$.

En lo que respecta a la arquitectura privada, se fecha en época de Augusto la construcción de las domus de Plaça Gran y Carrer de La Palma ${ }^{14}$. Los dos edificios presentan la misma organización cuidadosa del espacio y de las funciones, basada en la construcción de una planta articulada por un peristilo y en un programa ornamental que combina pavimentaciones en opus signinum y spicatum. Las dimensiones debían ser notables, ya que ambos parecen ocupar gran parte de una insula. Estos y otros posibles edificios señoriales se situan en la zona oriental del decumanus maximus, junto al centro político ${ }^{15}$. La parte alta de Iluro se configuraría, así, como espacio múltiple de actividad y representación de la élite local, en tanto que aquí parecen confluir vida política, poder social y residencia.

Las transformaciones del paisaje urbano podrían relacionarse con la promoción jurídica de la comunidad. Iluro se incluiría en la categoria de Municipium c. R.; en ese sentido han de interpretarse la inclusión entre los oppida c. R. del litoral de la Hispania Citerior (Plin. NH 3.4.22) y las evidencias epigráficas que mencionan instituciones municipales. En concreto, la inscripción CIL II 4616=IRC I, núm. 101, que alude a un duo vir quinquennalis. El momento de concesión de este estatuto es una cuestión debatida pues las fechas propuestas oscilan entre Augusto y los flavios. La datación flavia, generalmente admitida, ha sido cuestionada por Alföldy (1985: 416-417), quien propone una fecha augustea frente a la opinión de, entre otros, Le Roux ${ }^{16}$.

La importancia de los cambios obliga a preguntarse, en primer lugar, si pueden ser considerados como parte de una sistematización general determinada por un programa urbanístico. Cuestiones derivadas de la anterior son si el posible programa se ejecutó realmente en toda su extensión y quienes fueron sus promotores. La proximidad cronológica de las inscripciones y el significado simbólico y material de estas construcciones para la vida de la comunidad sugieren que se trata de una actuación urbanística global. Pero el valor de tales argumentos es relativo, ya que no conocemos las jerarquías y el funcio-

\footnotetext{
${ }^{13}$ Cerdà et al., 1997, vol. I: 265ss.; desarrollado en Cela, Revilla, 2004.

${ }^{14}$ Martí, Arxé, Cerdà, 1982-1983; Clariana et al., 1993 y Cela, García Roselló, Pera, 2003: 34 respectivamente..

${ }^{15}$ Pellicer, 1887: 239; Ribas, 1952: 90.

${ }^{16}$ 1985; discusión del documento en IRC V, suppléments, 23-24.
} 
namiento de la sociedad local y, por tanto, cuáles eran la capacidad económica y las necesidades de los promotores. De hecho, la construcción de estos edificios también pudo responder a un proceso más lento y ser el resultado de iniciativas individuales y menos coordinadas por el ordo local. La ejecución de estas obras podría dar igualmente la apariencia de una actuación programada.

Es difícil precisar cómo se integraron estos cambios en la estructura urbana republicana y hasta qué punto la modificaron. Las dimensiones y la función de las nuevas construcciones tuvieron que imponer forzosamente una reorganización del espacio y una articulación más rigurosa de las actividades; pero las evidencias de cambios en la arquitectura son escasas y ambiguas. También se constata el abandono de algunos edificios, pero no queda clara su relación con este proceso, como es el caso del posible macellum, aunque su abandono sea algo anterior. En este contexto, el sector sur del cardo maximus parece reforzar la función económica atribuida desde la fundación con la reforma de algunos espacios dedicados al comercio y los servicios (Cela, Revilla, 1999). En todo caso, el principado de Augusto y, de modo más general, la primera mitad del siglo I d.C. parece ser el momento en que se define una estructura urbanística relacionada con el funcionamiento de una comunidad cívica.

Durante el siglo I d.C. se producen reformas en edificios privados y comerciales que han de interpretarse como efecto de las reparaciones o de la adaptación de estructuras ya existentes a cambios de función puntuales. Tales reformas no alteran el paisaje urbano. No es hasta finales del siglo I d.C. y durante el II cuando se detecta un conjunto de cambios importantes en el registro arqueológico. Con todo, su significado es difícil de interpretar, ya que son de carácter muy diverso, no responden a intervenciones globales y afectan de forma muy diferente a la arquitectura, especialmente la de ámbito doméstico. En apariencia, la modestia material de los cambios haría pensar en procesos normales de reforma y conservación vinculados al mantenimento de los espacios residenciales y las infraestructuras relacionadas con los servicios colectivos; y, en efecto, algunos de ellos pueden revestir este caracter. Sin embargo, la consideración global de los restantes indica un carácter y un ritmo de desarrollo diferente respecto a las actuaciones puntuales ya indicadas.

Las transformaciones más numerosas afectan a la arquitectura privada. Un primer grupo está constituido por las reformas de pequeños espacios domésticos y por la desaparición de gran número de alcantarillas domésticas. ${ }^{17}$ En segundo lugar, las domus conocidas experimentan transformaciones muy importantes que se con-

${ }^{17}$ Cerdà et al., 1997, vol. I. cretan en expolios de elementos arquitectónicos o decorativos y en la construcción de nuevas estructuras, en las habitaciones o los peristilos, que deforman la clara articulación inicial entre residencia, representación y otras actividades ${ }^{18}$. La simplificación de los programas técnicos y ornamentales y la modificación del espacio parecen indicar la desaparición de tales domus como forma de residencia para la élite local; pero estos lugares siguen ocupados con posterioridad. Esta situación sugiere un cambio de función. El sentido y las características de este cambio se pueden apreciar en las vicisitudes que experimentan algunas domus de la cercana Baetulo, en las cuales se construyen instalaciones productivas a finales del siglo I-inicios del II ${ }^{19}$. Por el momento, no se puede establecer si estos cambios indican la desaparición general de la arquitectura privada señorial en Iluro.

También fueron reformados algunos edificios del sector sur del cardo maximus, aunque el sector mantuvo su función económica. Durante el primer cuarto del siglo II la zona oriental de una insula, ocupada anteriormente por una taberna, se divide en dos pequeñas unidades artesanales dedicadas, respectivamente, a la producción de objetos de hierro y de materiales constructivos (Cela, Revilla, 1999); hacia finales del siglo I o inicios del II se reforma un edificio muy cercano y se construyen dos grandes depósitos en opus signinum que parecen funcionar hasta los siglos IV-V ${ }^{20}$. Un hecho más importante es la construcción, en época flavia, de un edificio de grandes dimensiones y con una probable función termal al este del cardo maximus. Sus dimensiones y organización, mal conocidas por falta de una excavación adecuada, parecen alterar la estructura viaria y el alcantarillado de uno de los cardines orientales; como mínimo en su tramo final ${ }^{21}$.

Este conjunto de cambios podría relacionarse con una progresiva restructuración de la parte alta de la ciudad, donde se levanta una construcción de grandes dimensiones, quizá un pórtico, en un momento indeterminado de los siglos II-III (IRC V, suppléments, 47ss.).

\footnotetext{
18 Martí, Arxé, Cerdà, 1982-1983: 290; Clariana et al., 1993; Cela, García Roselló, Pera, 2003: 34.

19 Padros, 1985b: 155; Aquilué, 1987; abandonos y reocupaciones modestas de domus de Cartagena, a partir de la segunda mitad del siglo II y asociados a destrucciones, en Ramallo, Ruiz, 2000: 314; para Tarragona: Macias, 2000: 260ss.; Remolà, 2000a: 22-23 y 291; para Empúries: Castanyer et al., 1993: 191.

${ }^{20}$ Su uso concreto se desconoce (Cela, García Roselló, Pera, 2003: 23 y 29).

${ }^{21}$ Resumen de las excavaciones de 1964-1968, 1970 y 1987 en Pera, 1992: 5ss.; además Cerdà et al., 1997, vol. I: 259; el lugar presenta problemas de cronología e interpretación importantes y es difícil situar su funcionamiento en el contexto de la evolución de la vida urbana.
} 
Un dato revelador es que la base de una columna de esta estructura reutiliza fragmentos de las inscripciones pertenecientes a los primeros edificios del forum (IRC I, núms. 214, 216-217). Este hecho indica la desaparición total y temprana de una parte significativa del programa monumental de Iluro. Es posible, incluso, que algunos de los edificios dedicados en estas inscripciones no se hubiesen finalizado nunca y que esto facilitase la recuperación de materiales arquitectonicos. En todo caso, no se puede precisar el tipo de actuación y las necesidades con las que se relaciona esta nueva construcción: ¿una reforma o reorganitzación del espacio público ya existente? ¿Una obra nueva? Y, de ser así, ¿cómo se relacionaría con los edificios anteriores? Tampoco la cronología es muy precisa.

La situación de los siglos II-III d.C. no responde a una actuación global, si no que parece el resultado de un desarrollo lento en el que confluyen iniciativas muy diversas, en gran parte privadas, que se ejecutarían a ritmo distinto; dicho de otra forma, estas iniciativas muestran el proceso de adaptación de una comunidad urbana de pequeñas dimensiones, limitada a los recursos del territorio cercano, sin las aportaciones de evergetas importantes -por lo que podemos saber- y a condiciones socioeconómicas en mutación continua. Son, por lo tanto y en primer lugar, la expresión de una situación local. Es interesante señalar que ciudades próximas y de características semejantes, como Baetulo, experimentan transformaciones importantes desde época flavia ${ }^{22}$. Esta situación parece apreciarse también en otras ciudades romanas de Cataluña y esto lleva a interrogarse sobre la evolución general de las pequeñas sociedades urbanas provinciales en esta época ${ }^{23}$. No se puede interpretar este fenómeno en términos de decadencia. Por el contrario, existe la impresión de que Iluro, como otras ciudades, fue capaz de adaptar su funcionamiento interno a nuevas condiciones socioeconómicas y culturales y, paralelamente, de reajustar su posición respecto al territorio, reorganizando el conjunto de funciones administrativas, económicas e ideológicas que había asumido como municipium.

Uno de los rasgos que define la situación de los siglos II y III es lo que parece una mayor importancia de unas actividades económicas que se pueden definir como de servicios (artesanado) y pequeño comercio, organizadas de modo prioritario para satisfacer las necesidades de la población local y del territorio inmediato. Se trata de necesidades ligadas a la vida cotidiana y la producción, modestas y poco diversificadas. El inventario de estas actividades incluye el trabajo de los metales,

\footnotetext{
${ }^{22}$ Guitart, 1976; Padros 1985a-b y 1999; Aquilué 1987.

${ }^{23}$ Cf. Castanyer et al., 1993; para Tarraco, que presenta una situación diferente: Macias, 2000; a falta de estudios generales del fenómeno puede consultarse Guitart, 1993.
}

el material constructivo y el procesado y venta de productos alimentarios. La mayoría de instalaciones son de dimensiones y tecnología sencillas. Estas características y las condiciones de la demanda sugieren que estas unidades de trabajo concentrarían los procesos de fabricación y venta. La evolución de las actividades parece haber conducido a una intensificación del uso de los espacios disponibles que desdibujaría progresivamente la estructura del antiguo sector comercial, como resultado de la invasión del cardo maximus por algunas instalaciones y la compartimentación del interior de algunas insulae, para acabar sobrepasando quizá sus límites. Este proceso pudo haberse desarrollado de modo paralelo a la transformación de las funciones administrativa y de representación que la ciudad ejercía respecto al territorio. La mayoría de los cambios indicados se detectan en la cercana Baetulo: ocupaciones de domus por instalaciones productivas, en época flavia (Padros, 1985b: 155); transformaciones de tabernae vinculadas al forum, abandonadas a finales del siglo I y cubiertas por nuevos estratos en la primera mitad del II (Padros, 1985a; Aquilué, 1987: 19, 205); colmatación de alcantarillas públicas en la primera mitad del II (ibid., 80 y 85); abandono de domus hacia el tercer cuarto del II (ibid., 111).

En términos generales, la situación de Iluro parece reflejar el abandono de unas formas de vida que precisaban programas arquitectónicos y decorativos de gran entidad: por un lado, las construcciones monumentales que servían a la vida pública; por otro, la domus de peristilo. El abandono o transformación de estas construcciones parece coincidir con cambios en la sociedad local. Pero las evidencias al respecto son muy escasas e indirectas. Se ha señalado, en este contexto, la importancia que asumen los libertos en la vida local a partir de finales del siglo I y durante, como mínimo, la primera mitad del II d.C.; un hecho que evidencia claramente la epigrafía, ya que prácticamente todas las inscripciones del momento son de carácter religioso y están dedicadas a divinidades augusteas por libertos que desempeñan la función de sevir augustalis (inscripciones IRC I, núms. 97 a 100). Se trata seguramente de individuos enriquecidos que financiaron un ámbito importante de la vida cívica, la religión, pero de forma más modesta que en época augustea, ya que las actuaciones se refieren únicamente a aras y estatuas. No hay, por el contrario, evidencias de grandes construcciones (exceptuado el edificio con columnas ya mencionado, pero de cronología y función imprecisa) y, aun menos, de un programa global. Un problema especial lo supone la datación del programa musivario de las termas de Can Xammar, datado entre los siglos II y III, pero que podría corresponder a una actuación aislada (Pera, 1992: 30). Hay que decir que también algunas iniciativas urbanísticas importantes de la primera mitad del siglo I d.C. parecen 
promovidas por libertos, como muestran las inscripciones $I R C$ I, núms. 214 y 216, mientras que los miembros de la clase superior no aparecen claramente ( $c f$. la referencia al ordo iluronensium de IRC I, núm. 215). La situación del siglo II se caracteriza por la modestia de las actuaciones y por lo que parece una mayor presencia de libertos en un ámbito muy concreto: la religión. También es significativo que las inscripciones religiosas del siglo II mencionen siempre divinidades augusteas, lo que parece indicar un deseo de trascender el marco local y vincularse a la administración imperial. También se ha sugerido la actuación, o intereses, en el territorio de libertos importantes, como Lucius Licinius Secundus, accensus del senador Lucius Licinius Sura ${ }^{24}$. En este contexto, la presencia de miembros de los niveles sociales superiores es escasa y difícil de valorar: $I R C$ I, núm. 103, hallada en la villa de Torre Llauder y que menciona un eques de Barcino conocido a inicios del s. II (C. Marius Aemilianus); la ya mencionada IRC I, núm. 101 y la núm. 102, de un personaje desconocido, con una cronología dudosa que algunos investigadores llevan al siglo II.

A pesar de la falta de datos sobre la evolución socioeconómica del territorio, es factible pensar que los libertos dedicantes de las inscripciones ocuparon una posición dominante en la sociedad de Iluro como resultado de una combinación de actividad económica autónoma y la representación de los intereses locales de la aristocracia de Barcino, Tarraco y otras ciudades. Esta combinación llevaría a asumir una función de intermediación entre una ciudad y la aristocracia provincial o los representantes del poder imperial en la zona. Su posición debió favorecer una aparición relativamente frecuente en la vida pública mediante ciertas iniciativas. Sería excesivamente simplificador, por tanto, hablar de empobrecimiento de la comunidad de Iluro por el simple hecho de hallar a otros individuos en la posición de evergetas; tampoco puede pensarse en un cambio del orden social. Se trata, por el contrario, de una reorganización de las jerarquías locales motivada por factores diversos. No deja de ser significativo que sean siempre libertos quienes aparecen en la vida pública desde finales del siglo I d.C.-inicios del II y que sea en este momento cuando se datan las únicas menciones a patroni conocidas en el municipio (IRC I, núms. 98 y 105; además de IRC I, núm. 125). Como hombres de confianza de familias importantes, y por su éxito, estarían en mejores condiciones para asumir un mayor protagonismo público; un protagonismo indispensable para consolidar su promoción y la carrera de sus descendientes.

\footnotetext{
${ }^{24}$ La inscripción IRC I, núm. 125, localizada en S. Andreu de Llavaneres, al norte de Barcino, podría indicar la existencia de una propiedad en la zona.
}

En este contexto social, los escenarios y edificios en los que se desarrollaba la actividad pública debieron experimentar modificaciones profundas. La promoción de nuevos individuos entre el grupo dirigente local, con unas posibilidades económicas, expectativas de carrera y cultura diferentes respecto a la élite de la primera mitad del siglo I d.C., debió de generar unas necesidades de autorrepresentación específicas y las iniciativas promovidas por tales personajes en relación al funcionamiento de la vida de la comunidad debíeron de cambiar de modo significativo; pero no estamos ante una crisis general. En este sentido, son reveladoras las transformaciones de las domus: mientras que estas son expoliadas o reconvertidas a actividades productivas en el siglo II, algunas villae suburbanas mantienen plenamente los rasgos de la arquitectura residencial encargada por la élite. En el caso de la mejor conocida, Torre Llauder, a finales del siglo II o inicios del III se produce una reconstrucción general, que incluye un programa musivario muy complejo (Prevosti, Clariana, $1993^{2}$ : 15). La evolución divergente de la arquitectura residencial urbana y rural, aun más significativa si puede relacionarse con la presencia de equites de Barcino a partir de inicios del siglo II, podría indicar una cierta relajación, resultado del alejamiento, de las relaciones entre ciertas familias aristocráticas y la ciudad de Iluro.

\section{LA DEFINICIÓN DE UN NUEVO HÁBITAT: ILURO ENTRE LOS SIGLOS IV Y VII D.C.}

Durante la antigüedad tardía el antiguo municipium, o una parte del mismo, permaneció ocupado de forma estable. El registro estratigráfico y los datos materiales sugieren que esta ocupación se prolongó hasta un momento impreciso del siglo VII d.C. (Cela, Revilla, 2004). La arqueología permite rechazar las reconstrucciones catastrofistas que mantenía la historiografía local hasta época reciente y muestra, por el contrario, una imagen más compleja del hábitat en la antigüedad tardía ${ }^{25}$. Este hábitat se integra en el contexto de una profunda tranformación de la topografía, el espacio y la arquitectura de la ciudad altoimperial. En este sentido, parece haber una diferencia de naturaleza entre la situación de Iluro hasta el siglo IV y quizá las primeras décadas del V, que podría definirse como de continuidad del modelo urbano, con unos límites materiales e ideológicos evidentes, y la ocupación de los siglos VI-VII (Cela, Revilla, 2004: 407ss.). El ritmo y entidad de los cambios no fue determinado por acontecimientos político-

${ }^{25}$ La decadencia como tema en: Pellicer, 1887: 373ss.; Ribas, $1988^{2}$ : 194, 202ss.; id. 1975: 17, 29, 35ss; para el trasfondo cultural de esta historiografía Cela, Revilla, 2004: 21ss. 
militares, si no que resultan de la convergencia entre factores generales (la evolución socioeconómica y cultural del mundo mediterraneo) y la situación local ${ }^{26}$. La cuestión principal no es, en consecuencia, comprobar la continuidad del hábitat en el espacio que correspondía al antiguo municipio, sino definir la naturaleza exacta de unos procesos de ocupación que presentan rasgos particulares y los factores que los determinan.

La primera dificultad que plantea este objetivo proviene de la propia documentación arqueológica. Las excavaciones han aportado un volumen de evidencia muy importante, pero difícil de interpretar. En primer lugar, como resultado de las condiciones en que se desarrolla la práctica arqueológica en Mataró (como en otras ciudades), los sectores excavados, con pocas excepciones, son de dimensiones reducidas y aportan secuencias estratigráficas limitadas, con problemas de conservación a partir de los siglos IV y V. Además, las estratigrafías identificadas están aisladas y no se puede establecer si son el reflejo de situaciones específicas o si, por el contrario, indican procesos de carácter más general.

En segundo lugar, la evidencia recogida en las últimas décadas corresponde de forma casi exclusiva a dos fenómenos distintos. Por un lado, un conjunto de estratos de nivelación que se concentran en la zona del cardo maximus, cubriendo esta vía y los edificios adyacentes. $\mathrm{Su}$ importancia es evidente, pero no es fácil determinar el ritmo y sentido de estas actuaciones, ya que ocupan un periodo de tiempo bastante amplio (la segunda mitad del siglo V y el primer cuarto del VI) y apenas se acompañan de evidencias constructivas que permitan imaginar cómo se organizó el espacio y a qué necesidades se respondía. Algunas actuaciones podrían responder a iniciativas particulares; otras podrían resultar de una acción más sistemática, quizá planificada, sobre espacios definidos (Cerdà et al., 1997, vol. II: 123ss.; nuevas evidencias y revisión en Cela, Revilla, 2004: 45ss.). Las implicaciones de la segunda posibilidad para definir la naturaleza del asentamiento, en términos de ritmo y organización de esfuerzos, son importantes. Tampoco se puede excluir la existencia de iniciativas distintas dentro de un proceso general de cambio. Finalmente, no es fácil precisar la relación entre los depósitos del cardo y otras acciones en lugares cercanos; por ejemplo, la posible vinculación con la evolución del espacio del forum; y más concretamente, con la constitución y abandono posterior de un conjunto de silos (Plaza de Santa María), así como con un pequeño conjunto de inhumaciones (Plaza del Fossar Xic), que parecen corresponder a la

\footnotetext{
${ }^{26}$ La diversidad de líneas de evolucion del fenómeno urbano se destaca en: Brogiolo, Ward-Perkins 1999; Brogiolo, Gauthier, Chriestie, 2000.
}

fase inicial de un cementerio cristiano constituido dentro de la antigua ciudad. El segundo fenómeno está representado por un conjunto de fosas excavadas durante el siglo VI que fueron colmatadas en diversos momentos de la misma centuria o a inicios de la siguiente. Estos depósitos aportan una imagen muy rica de la cultura material del periodo, pero también limitada, ya que se trata de vertederos domésticos no especializados. Su formación y composición indican, ante todo, los procesos de vida cotidiana y producción de unidades familiares. Tampoco es posible, por el momento, relacionar los vertederos con estructuras arquitectónicas.

La mayor parte de datos disponibles en la actualidad se concentra en el centro de la ciudad, en el cruce entre cardo y decumanus maximi, así como en la zona norte y oriental, donde se situan las domus conocidas y el forum. En todo este espacio se aprecian cambios materiales y de función que provocarán una transformación radical del paisaje y que definen una nueva relación del hábitat con la estructura urbanística anterior. El hecho de que las transformaciones afecten especialmente a estas zonas no parece casual (cf. Gurt, 1999 y 20002001). Pero esta concentración de la evidencia también podría crear una imagen distorsionada de la evolución del hábitat en Iluro y dar, por ejemplo, la impresión de que la ciudad experimentó simplemente un proceso de contracción de la superficie ocupada. Esta posibilidad no se puede excluir, pero de confirmarse tan sólo sería uno de los factores que caracterizan un proceso más amplio. Como muestra la situación de otras ciudades hispanas, las transformaciones afectan globalmente el interior de los recintos urbanos y el área del suburbio, pero con ritmos y efectos diversos que crean un paisaje nuevo definido por el policentrismo y la fragmentación de las tramas urbanas ortogonales que habían organizado el espacio urbano de modo regular (Gurt, 2000-2001: 444.; Cantino-Wataghin, 1999: 153-154).

El primer fenómeno a destacar son los cambios que afectan el urbanismo y, más concretamente, la retícula ortogonal y la estructura viaria. Estos cambios son indisociables de la evolución de la vida local e indican su dinamismo. Ya se ha indicado que la ciudad fue modificando su urbanismo inicial desde el mismo siglo I a.C. y que este proceso continuó durante los siglos I y II d.C., pero sin alterar la organización global. Esta estructura debió de mantener su utilidad hasta un momento impreciso del siglo V (¿mediados?); por lo menos en lo que hace al cardo maximus, donde se han identificado reparaciones de la alcantarilla principal durante el siglo IV y un estrato que amortiza un sector de la calle a finales del siglo IV-inicios del V. Muy cerca, en el cruce del cardo con un decumanus secundario, la acera fue reformada en ese mismo momento. La calle y el edificio situado a occidente fueron cubiertos por un estrato de destrucción que se data algo después (Cela, Revilla, 2004: 50 y 74). 
No se dispone de otras evidencias entre este momento y los estratos que amortizan definitivamente el cardo maximus y que se datan en la segunda mitad/finales del siglo V-primer tercio del VI (ibid., 163ss.). La constitución de estos estratos confirma la eliminación simultania de la vía y de las construcciones que la delimitaban, lo que supuso la desaparición absoluta de una parte importante de la organización urbanística original.

Por ahora, no se puede establecer qué sucedía contemporáneamente en las vías restantes. Es posible que una parte se mantuviera en uso, mientras que otros tramos serían invadidos y la circulación interrumpida. De hecho, ya en el siglo II existe constancia de construcciones porticadas en la zona sur del cardo maximus que muestran que la invasión de los ejes viarios no es un fenómeno exclusivo de época tardía ( $c f$. Gurt, 20002001: 445ss.; id. 1999: 65-66). Es probable que vías principales y secundarias siguiesen una evolución diferente y que algunos cardines y decumani minores, de menor importancia, o situados en zonas periféricas, fuesen ocupados muy pronto. En todo caso, el proceso de desaparición de la mayoría de vías ha finalizado hacia finales del siglo V-inicios del VI, como demuestra la distribución de las escasas construcciones que se levantan sobre estratos de esta cronología, de hasta un metro de espesor y que cubren totalmente los edificios antiguos. Igualmente, algunas construcciones identificadas en la Plaza de l'Ajuntament parecen invadir un cardo minor interrumpiendo totalmente la circulación ${ }^{27}$. A lo largo del siglo VI, se excavaron las fosas ya mencionadas, ocupando indiferentemente vías y espacios domésticos (Cela, Revilla, 2004: 251ss.).

Simultaneamente, otras vias de la trama original parecen haber sido conservadas y desviadas. Este hecho se aprecia en el decumanus maximus, que se desplazó hacia el norte aproximadamente a medio camino de su recorrido, en el punto más cercano al forum de la ciudad. La alineación de las actuales calles de Baixada de Sant Simó (que mantiene hoy día la orientación original), Beata María y Carrer Nou parece fosilizar el nuevo itinerario. No se puede establecer la cronología de este cambio que, en cualquier caso, debía ser el resultado final de un proceso prolongado, y tampoco los motivos ${ }^{28}$. El fenómeno se podría relacionar con la transformación que experimentó el espacio actualmen-

\footnotetext{
27 Estas construcciones se han datado, sin demasiadas garantías, en el siglo V (Arxé et al., 1986: 80-81); una propuesta sobre el sector, que podría ser modificada por nuevos hallazgos, en Cerdà et al., 1997, vol. I: 256ss., esp. 262.

28 Cerdà et al., 1997, vol. I: 264-265, mencionan la posibilidad de una actuación medieval o, más probablemente, anterior; para las pervivencias medievales y modernas de la ciudad romana: ibid., 270ss.
}

te ocupado por la basílica y Plaza de Santa María y con un nuevo uso comunitario (vid. infra). Un hecho relacionado con los cambios en la organización del espacio es la elevación general de la topografía del hábitat. Este fenómeno se detecta en numerosas ciudades tardías y no se puede atribuir simplemente a destrucciones ${ }^{29}$. En el caso de Iluro, las aportaciones se concentran en el sector sur del cardo maximus y afectan a un espacio importante, ya que se detectan en puntos separados hasta $100 \mathrm{~m}$. entre sí, cubriendo todas las estructuras anteriores y cancelando la antigua distinción entre calles o espacios abiertos y edificios.

La transformación del antiguo espacio urbano afectó especialmente a las infraestructuras públicas que utilizaban la red viaria; en particular, el alcantarillado. Una parte de este, en la confluencia entre cardo y decumanus maximus, se había abandonado ya a finales del siglo IIIinicios del IV (Cerdà et al., 1997, vol. I: 256ss.). Por el contrario, el tramo sur de la misma alcantarilla seguía funcionando después de una reforma que se data en el segundo cuarto-mediados del siglo IV. Esta infraestructura ha seguido conduciendo agua hasta época contemporánea; pero se trata seguramente de un funcionamiento casual, ya que no se han identificado aquí las actuaciones de reforma o las reconstrucciones tardías de infraestructuras que se conocen en otras ciudades (Gelichi, 2000: 16-17). Es importante señalar que la desaparición de las infraestructuras de desagüe es un proceso que se inicia muy pronto, durante el siglo II, y que se desarrolla en el contexto de la continuidad, transformada, del antiguo urbanismo hasta el siglo V (para otras ciudades de Hispania: Gurt, 2000-2001: 445). La transformación del alcantarillado, en realidad, se relaciona con la dinámica que sigue el municipio imperial. La constitución del hábitat de los siglos VI-VII parece ser independiente de las posibilidades que tales infraestructuras podían ofrecer todavía; como es el caso de algunas ciudades de Italia (La Rocca Hudson, 1986: 64-65 y 70; Brogiolo, 1989: 313ss.; Gelichi, 2000: 16ss.). La ruptura entre la situación del siglo IV y el nuevo hábitat parece, en este sentido, más radical en Iluro que en otros lugares. Este hecho puede responder a la desaparición de algunas de las funciones materiales e ideológicas de la ciudad y a otros factores (problemas económicos o una reducción de la población, por ejemplo) durante los siglos III y IV, lo que haría inútil y costoso el mantenimiento de algunos de los servicios propios de una ciudad clásica.

Otro fenómeno importante en la Iluro tardía es la reorganización de las actividades productivas y las funciones ideológicas que concentraba el lugar y, en relación

${ }^{29}$ La Rocca Hudson 1986: 70ss.; para Hispania Fuentes, 1999; Gurt, 2000-2001: 449-450; para Baetulo: Padros, 1999: 90. 
con ello, la redefinición de sus relaciones mutuas. Este cambio supone una restructuración del espacio y la creación de nuevos emplazamientos. El desarrollo del proceso y los rasgos que lo caracterizan muestran algunos de los principios materiales e ideológicos que inspiran las nuevas formas de organización de la vida de la comunidad. En un momento mal definido, pero que se situaría en el siglo IV, una parte de la superficie del antiguo forum fue ocupada por silos. La pésima conservación de estas estructuras impide precisar sus dimensiones y la organización del sector y no se puede establecer ni la capacidad de almacenamiento ni la posible presencia de instalaciones de transformación ${ }^{30}$. Tampoco se ha podido conocer la duración total de la ocupación y los escasos rellenos de silos datados aportan cronologías de segunda mitad de siglo IV y finales del V-inicios del VI. También ha aparecido silos que aportan dataciones de los siglos III/IV, pero son poco fiables (Cela, Revilla, 2004: 326-327). Con todo, es evidente que la invasión de un antiguo espacio de representación por ciertas actividades económicas constituye un fenómeno de gran importancia.

Las actividades económicas (artesanales y comerciales) que ofrecía el municipio del alto imperio se localizaban en espacios periféricos, segregadas respecto a la vida política y social. Pero a la vez, la economía se integraba perfectamente en la trama urbana y su arquitectura. La situación se modifica en parte durante la primera mitad del siglo II, como muestran las reformas del sector sur del cardo maximus ya mencionadas. La constitución de una zona de almacenamiento en la zona del forum supone una situación nueva, de hecho, una auténtica sustitución de las funciones, que conduce a la modificación de la organización espacial anterior. Esta transformación del centro cívico corresponde a una fase avanzada del proceso de desaparición de la forma de vida municipal; si es que no indica el final de este proceso. Un problema importante es el ritmo del fenómeno, ya que, paralelamente, existen evidencias de mantenimiento de infraestructuras y de la red viaria. La coincidencia de estos factores permite calificar el periodo que cubre el siglo IV (quizá desde finales del III) y las primeras décadas del V como un momento clave de transformación de la ciudad y demuestra que el proceso no siguió un desarrollo lineal, ya que coexisten iniciativas diversas (reparaciones, expolios y reocupaciones) y estas actuaciones parecen afectar de forma diversa los espacios y edificios de la ciudad en función de su utilidad para la vida colectiva (fig. 3).

Tampoco es casual que no se trate de una actividad cualquiera: el centro de la antigua ciudad sirvió, ante

\footnotetext{
${ }^{30} \mathrm{La}$ asociación de silos, depósitos y prensas ha sido bien documentada en algunas aglomeraciones rurales situadas en el litoral de Barcelona (Morer, Rigo, Barrasetas, 1997: 90ss.).
}

todo, para almacenar excedentes; no se han localizado otras fases del proceso productivo agrícola, aunque no se pueden excluir la existencia de actividades de procesado; y todavía menos actividades no-agrícolas. No se puede evaluar la capacidad de almacenaje del lugar, ya que quizá no todos los silos funcionaron de forma simultánea y otros pueden haber desaparecido; pero no parece tratarse de un fenómeno de poca entidad, ni de una concentración casual de depósitos privados. La constitución de esta zona de almacenamiento parece responder a unas necesidades comunitarias de control y redistribución de una parte del excedente agrícola con fines diversos: consumo local; fiscalidad; inserción en circuitos de intercambio por venta directa o salida como rentas. En esta situación habrían intervenido los poderes locales mediante mecanismos diversos que no se pueden determinar (rentas, contribuciones). La concentración de excedentes agrícolas en Iluro indicaría que ésta todavía mantenía una posición central respecto al territorio, sustituyendo la anterior función administrativa por el control de una fase fundamental de los procesos de producción. La potenciación de la función agrícola, paralela a la desaparición de la rígida organización ortogonal, muestra tambien que la antigua distinción entre campo y ciudad (ésta, entendida como lugar de cultura y residencia de élites) está perdiendo su sentido.

Igualmente importante, por lo que respecta a la organización de la vida colectiva, es la creación de áreas funerarias en el interior de Iluro $^{31}$. La más importante se situó en el espacio que había correspondido al antiguo centro político (fig. 4). El cementerio ocupa una superficie mínima de $8000 \mathrm{~m}^{2}$, entre las actuales plazas de Santa María y del Fossar Xic, que en época medieval y moderna mantuvieron esta función funeraria, y se extiende al norte. Hasta el momento se han localizado unas 40 inhumaciones que presentan un ritual bastante uniforme, a pesar de las marcadas diferencias de tipología y técnica constructiva que caracterizan los enterramientos. Con excepción de cuatro casos, todos los enterramientos se orientan en sentido O-E, con la cabecera hacia el Oeste. En ninguno de ellos se han recogido ofrendas y tampoco hay evidencias de elementos ornamentales. La mayoría de estructuras, con la excepción de algunos panteones verticales y uno horizontal, corresponde a inhumaciones individuales. Las pocas cronologías disponibles, relacionadas con estructuras y depósitos afectados por las tumbas, se sitúan en los siglos V e inicios del VI; pero es muy probable que algunos sectores de esta zona fueran utilizados ya en un momento anterior. Es el caso de un conjunto de tumbas de tegula en el Fossar Xic, que se situarían en los siglos IV-V. Otros sectores, por el contrario, podrían haber

\footnotetext{
${ }^{31}$ Un análisis global en Cela, Revilla, 2004: 315ss.
} 


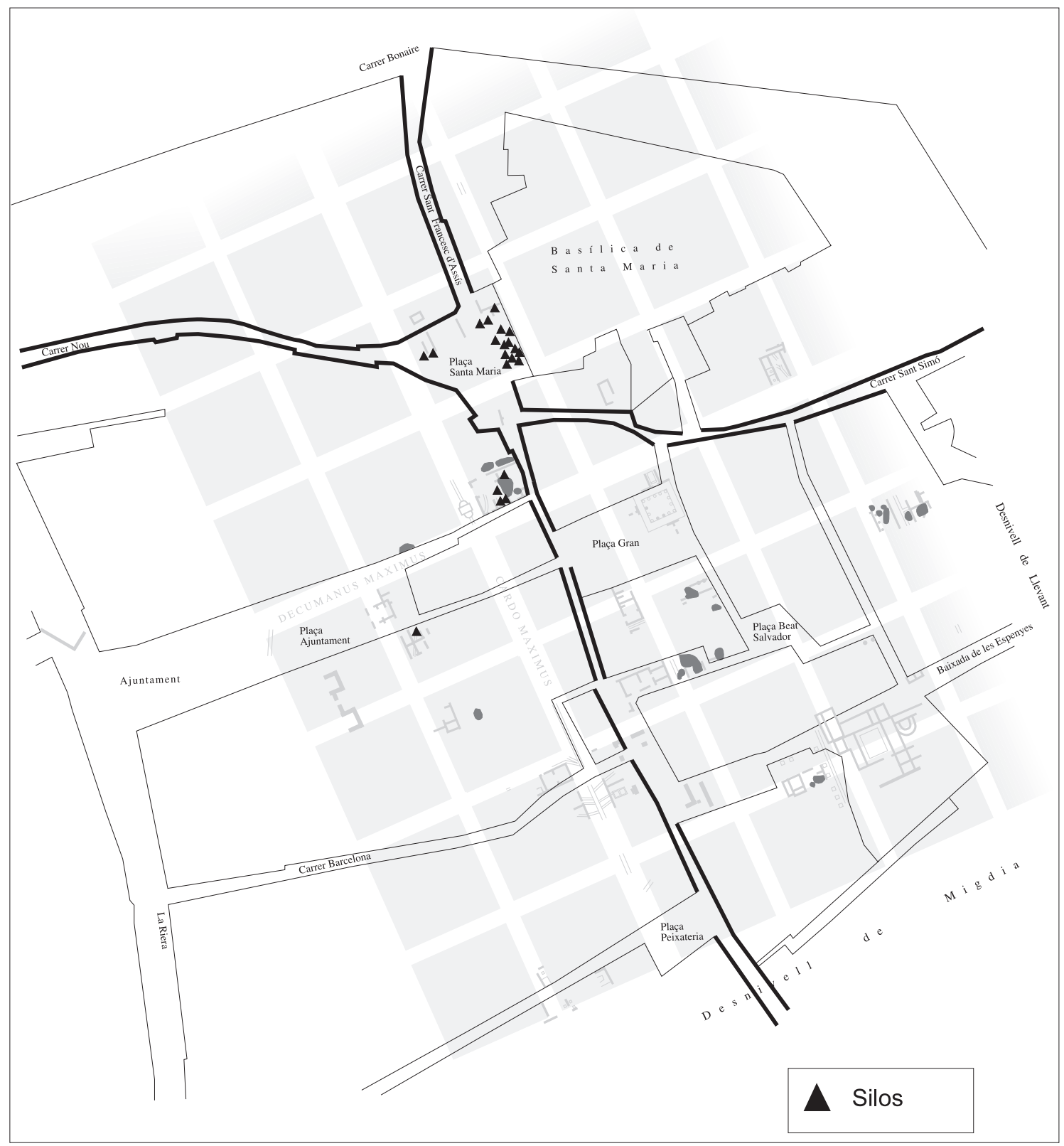

Figura 3. Distribución de los silos y de las fosas tardías sobre la antigua ciudad romana. Se indica en línea gruesa la orientación de los posibles ejes viarios tardíos.

continuado en uso hasta finales del VI y durante el VII. Las diferencias de datación y tipología sugieren una evolución en la ocupación del espacio disponible, aunque el proceso no se puede reconstruir totalmente (Cela, Revilla, 2004: 315-316). Esta ocupación ignora totalmente la estructura urbanística original.

Los casos de conversión de espacios públicos y privados en zonas de uso funerario son numerosos y muestran diferencias relacionadas con la evolución de la vida colec- tiva de cada lugar ${ }^{32}$. Así, en Iesso (Guissona), este nuevo uso afecta a una zona originalmente ocupada por viviendas (Pera, 1996-97). En un sentido diferente, parte de la

${ }^{32}$ Factores y significado de este tipo de fenómenos en Cantino-Wataghin, 1999; para Roma: Meneghini, Santangeli Valenziani, 1993; Meneghini, 2003: 1055; para Hispania: Gurt, 1999: 73; id. 2000-2001: 462; Castellanos, 2000, destaca la importancia del culto a los mártires. 


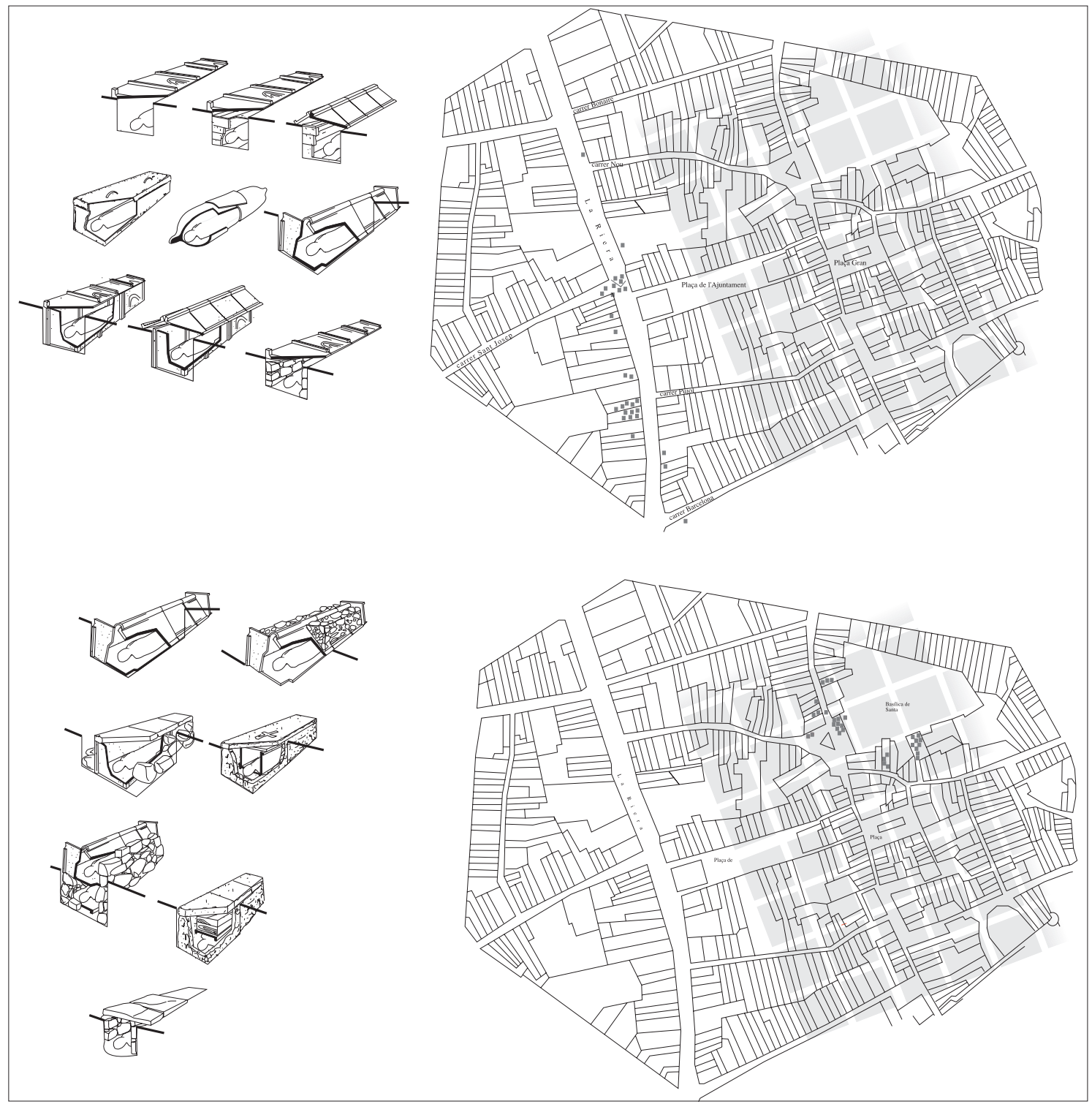

Figura 4. Distribución de las tumbas conocidas de la necrópolis de Iluro (arriba) y de la necrópolis tardía (abajo), con los principales tipos de inhumaciones.

neápolis ampuritana, ya deshabitada, fue ocupada por un cementerio que fue utilizado por la población de la cercana Sant Martí d'Empúries entre los siglos IV y VIII (Nolla, Sagrera, 1995). En el caso de Pollentia, la zona que corresponde a la necrópolis es el forum y la transformación se data a inicios del siglo IV d.C. (Arribas, Tarradell 1987: 135-136). En Tarragona, por el contrario, los cementerios se sitúan y organizan en la periferia de la ciudad, en torno a los centros de culto, mientras que en el interior los enterramientos están dispersos, ocupando edificios públicos anteriores (Gurt, 2000-2001: 462-463). Es imposible precisar los factores que determinaron la elección del lugar, pero el caso de Iluro parece responder, como en tantas ciudades, a las facilidades asociadas a la existencia de un espacio libre de construcciones y con poca densidad residencial y que, por su caracter público original, sería susceptible de un nuevo uso comunitario. El temprano abandono o restructuración de la zona, incluidas las domus cercanas, habría facilitado el nuevo uso. Un problema pendiente es el de la relación entre silos y necrópolis. El único caso en que ha sido posible establecer una relación estratigráfica directa entre silos y enterramientos ha mostrado que estos eran posteriores (Cela, Revilla, 2004: 327-328); pero esto sólo se aprecia en un sector del cementerio. 
Por el contrario, es posible que las primeras inhumaciones en el Fossar Xic, relativamente distantes, fuesen contemporaneas con el uso de los silos.

También se han localizado algunos enterramientos tardíos que reutilizan espacios y construcciones de la necrópolis altoimperial situada en el exterior de la ciudad, al Oeste (Cela, Revilla, 2004: 315-316). Su cronología exacta no se puede precisar, pero parecen situarse en los siglos IV y V. Tampoco se puede establecer si se trata de un espacio cementerial definido o de enterramientos esporádicos; pero en todo caso su uso parece haber sido contemporáneo, por lo menos durante un periodo, respecto al funcionamiento de la necrópolis de Santa María. Esta multiplicación de áreas de enterramiento, incluidas lo que parecen inhumaciones dispersas, y la reutilización funeraria de ciertos espacios y construcciones contribuyó a la desaparición definitiva de la distinción entre ciudad y periferia ${ }^{33}$.

A pesar de la modestia general, el cementerio de Iluro muestra la existencia de diferencias sociales en la comunidad; ejemplos de ello son una tumba cubierta por un revestimiento de opus signinum decorado con un crismón y algunas inhumaciones colectivas protegidas por una construcción muy sólida ${ }^{34}$. Además, la disposición de las tumbas muestra un orden y una orientación cuidadosas y una tendencia a la concentración en un sector muy concreto. Estos hechos indican una diferente valoración del espacio disponible y una situación de competencia por su apropiación.

El evidente carácter cristiano de algunas tumbas y la organización del espacio ocupado, así como la importancia de algunos enterramientos, sugieren un proceso de control organizado por una jerarquía y la asociación de esta práctica con la presencia de un edificio de culto en las cercanías. Los posibles mecanismos para ejercer este control son evidenciados por las referencias a la deposición ad sanctos que aparecen en las inscripciones cercanas de Sant Martí de Mata, que corresponderían a un centro de culto y un cementerio que podría relacionarse con la organización del poblamiento del territorio al norte de Iluro, junto a las primeras estribaciones de la cordillera litoral ${ }^{35}$. Muy cerca de este lugar se situaba la necrópolis de Ca la Madrona, formada aparentemente

${ }^{33}$ Cf. Meneghini, Santangeli Valenziani, 1993; Meneghini 2003; ejemplos de coexistencia de cementerios dentro de recintos urbanos y en el suburbium, en ocasiones prolongando un uso anterior, en Gurt, 1999: 73.

${ }^{34}$ Para la primera de estas tumbas: Ribas, 1975: 79-80, lám. II y fig. 39; cubiertas en opus signinum, decoradas con crismón, datadas en la segunda mitad del siglo VI en: Nolla, Sagrera, 1995: 248; Ulbert, Orfila, 2002.

${ }^{35}$ Estas inscripciones (IRC I, núms. 123 y 124) se datan en el primer tercio del siglo VII, una cronología que coincide con las evidencias de ocupación en el casco histórico de Mataró. por docenas de tumbas, para la cual se propone una cronología de siglos VII-VIII (García Roselló, Cerdà, 1990). Es muy posible que en Iluro el espacio funerario también fuera articulado por un centro de culto y que los poderes religiosos utilizaran mecanismos similares. Por desgracia, no existen evidencias materiales relacionadas con un edificio religioso, con excepción de un fragmento de cancel recuperado en las excavaciones realizadas en la cercana Plaza de l'Ajuntament. Un argumento complementario, de relativo valor, es la continuidad del culto en el lugar, testimoniada por los sucesivos templos románico, gótico y barroco de Santa María ${ }^{36}$. Más importante parece la propia organización de los enterramientos y, en primer lugar, la posición central de la tumba cubierta por un crismón, que debía pertenecer a un personaje destacado. Su posición social y funciones en vida, imposibles de precisar, fueron suficientes para asegurarle el respeto póstumo y la memoria a través de una sepultura privilegiada que parece determinar otros enterramientos. Este respeto muestra la existencia de unas jerarquías sancionadas por la religión, a la vez que indican la importancia de ésta, y de las manifestaciones asociadas (inhumación en cementerios organizados), en la vida comunitaria. La combinación de culto y espacio funerario pudo servir, igualmente, para potenciar el papel de Iluro respecto al territorio cercano.

Con la disgregación del urbanismo original también desaparecieron las formas arquitectónicas propias de la ciudad republicana y altoimperial; formas que se habían caracterizado por sus soluciones técnicas y ornamentales (mosaico, opus signinum y spicatum), los materiales (mortero, ladrillo, tejas) y los modelos constructivos que organizaban el espacio y las funciones de forma rigurosa y regular. Desaparecen por completo, en primer lugar, las agrupaciones de pequeños espacios comerciales y las domus. El proceso, que se había iniciado en el siglo II, se ha completado a finales del siglo V-inicios del VI, cuando gran parte del cardo maximus es cubierto por estratos de nivelación. Sin embargo, se desconoce cómo evoluciona la arquitectura de la ciudad entre estas dos fechas y no se puede pensar simplemente en una decadencia y empobrecimiento gradual. Algunos lugares mantuvieron algún tipo de ocupación estable que muestra una diversidad de situaciones relacionada con factores por ahora desconocidos. Así, en la antigua zona comercial del cardo maximus, un depósito es abandonado entre mediados-segunda mitad del siglo IV, mientras que otro muy cercano es amortizado en la segunda mitad del V, cuando el cardo es definitivamente cubierto (Cela, Revilla, 2004: 74).

${ }^{36}$ Para las posteriores construcciones medievales y modernas: Cerdà et al., 1997, vol. I: 270ss.; las relaciones entre edificios de culto y necrópolis se describen en Gurt, 1999: 71; más en general Cantino-Wataghin, 1999: 153ss., esp. 158-160. 
Las construcciones conocidas son muy escasas y no es posible precisar su función y su cronología; más allá de su atribución genérica al siglo VI. Hasta el momento, tan sólo en dos lugares del antiguo espacio urbano se han localizado muros que parecen delimitar ámbitos de planta rectangular, alargada y estrecha. En uno de estos lugares, los muros se disponen paralelamente, sugiriendo una alineación de pequeñas unidades habitacionales; su cronología es posterior a la formación del estrato de amortización del cardo maximus: inicios del VI ${ }^{37}$. Ninguna de estas construcciones se conservaba en buenas condiciones, por lo que su restitución es totalmente hipotética. A este reducido conjunto se pueden añadir algunos muros y pavimentos, datados sin demasiada precisión en los siglos IV-V, a occidente de la ciudad. Un hecho interesante es la presencia de vertederos cerca de estas estructuras, también con una cronología de siglo V (Arxé et al., 1986: 80-81). La obra es siempre muy pobre: los muros, en tapial, se levantaron sobre una base de material en su mayor parte reutilizado: pequeños bloques de piedra que incluyen fragmentos de mármol, tegula, fragmentos de cerámica. Probablemente, las cubiertas eran de materiales vegetales.

La información actualmente disponible no permite establecer la función de estas estructuras. Tampoco ha sido posible establecer una relación directa con el conjunto de fosas excavadas en el siglo VI. Con todo, parece posible considerar estas construcciones como elementos del hábitat tardío y, más concretamente, como unidades de habitación. Tanto los materiales como la tipología corresponden a una práctica identificada en asentamientos rurales de Cataluña, como Vilaclara de Castellfollit, Can Paleta y La Solana ${ }^{38}$. Todos ellos se definen por integrar edificaciones de dimensiones reducidas, aisladas o agrupadas en conjuntos de 2 o 3 unidades, con una planta que tiende al rectángulo. Los materiales son modestos y raramente se utilizan el mortero, los sillares y el ladrillo. En el caso más complejo, La Solana, las construcciones estaban rodeadas por silos, prensas (con depósitos en opus signinum), hornos y otras estructuras de combustión, así como fosas y espacios excavados en el terreno, que se distribuían de forma irregular por una amplia superficie, y algunas inhumaciones. Esta distribución aparentemente anárquica responde a una organización del hábitat en la que las antiguas formas residenciales, asociadas a la forma de vida de un grupo social, han perdido su importancia y que concentra un amplio espectro de actividades productivas

${ }^{37}$ Cela, Revilla, 2004: 74 y lám. 17; para una cronología y características más imprecisas en la misma Iluro: Cela, Revilla, 2004: 149 y lám. 59.

38 Enrich, Enrich, 1995; Morer, Rigo, Barrasetas, 1997; para las transformaciones del hábitat rural en el NE de la Tarraconense Navarro, 1999: 118ss. cuya finalidad es asegurar el funcionamiento autónomo de un asentamiento (ejemplos en el interior de la península en Vigil, 2000). El hábitat urbano presenta rasgos similares (Ramallo, 1996; Ramallo, Ruiz, 2000: 314; Gurt, 1999: 69; id., 2000-2001: 459 y 461): dimensiones reducidas y tendencia a la compartimentación, simplicidad tipológica, con unidades residenciales formadas por pocas habitaciones y un patio, modestia constructiva; $y$, finalmente, presencia de actividades diversas.

Tampoco se dispone de información sobre la situación que presentarían, en este momento, algunas de las construcciones públicas más representativas, como las termas y las murallas. En el caso de las primeras, el hallazgo de una fosa que contenía fragmentos de una estatua que pudo formar parte del programa decorativo original, indica una frecuentación esporádica del lugar relacionada, por lo menos en parte, con procesos de expolio; pero tampoco puede excluirse la existencia de un hábitat estable o una fase limitada de ocupación ${ }^{39}$. Por desgracia, no se puede precisar el estado general del edificio en ese momento. Por lo que hace a la muralla, una excavación reciente ha aportado evidencias de algun tipo de continuidad hasta el siglo $\mathrm{V}$, sin que se pueda precisar la situación del recinto en un momento tan avanzado (Cela, García Roselló, Pera, 2003: 24).

Hasta el momento, las únicas construcciones sólidas localizadas son las destinadas al enterramiento, en las que se utiliza piedra mezclada con mortero y revestimientos en opus signinum (Cela, Revilla, 2004: 314ss.); a ello habría que añadir el fragmento de cancel, que se asociaría a un edificio. En este contexto, a pesar de la falta de evidencias más sólidas, se podría hipotetizar que en Iluro también se produciría la diferenciación material entre construcciones privadas y públicas que caracteriza el desarrollo arquitectónico de las ciudades tardías y que determina, en gran parte, el ritmo y el carácter selectivo de las acciones de expolio ( $\mathrm{La}$ Rocca Hudson, 1986: 64ss). La modestia de las construcciones y de las instalaciones relacionadas con la vida cotidiana es un rasgo señalado por todos los investigadores ${ }^{40}$. También en los asentamientos rurales se aprecia un claro contraste entre la modestia de las construcciones residenciales y la solidez de otras estructuras, generalmente instalaciones productivas (Morer, Rigo, Barrasetas, 1997: 90ss.). Este hecho indica claramente cuales son los intereses de la comunidad y las estrategias que desarrolla para utilizar mejor sus recur-

\footnotetext{
${ }^{39}$ Para las relaciones entre expolio y reocupaciones privadas de edificios públicos: Gurt, 2000-2001: 451-452

${ }^{40}$ En Hispania, un buen ejemplo es la ocupación del teatro de Cartagena: Ramallo, Ruiz, 2000: 314; además Gurt, 20002001: 458ss.; para otras regiones del imperio: Brogiolo, 1989: 160-161; Demians D'archimbaud, 1994: 44 y 47; Murialdo, Bonora 2001: 175ss.
} 
sos: la recuperación y el reciclaje, la diversificación de estrategias y prácticas y, finalmente, la concentración de los esfuerzos en ciertos ámbitos.

La evolución de la arquitectura y de la cultura material de Iluro también muestra un rasgo característico de la dinámica del hábitat en las ciudades tardías: los procesos de expolio y reutilización (La Rocca-Hudson, 1986: 64-65; Brogiolo, 1989: 158ss.; Gurt, 1999: 66-67; id. 2000-2001: 450ss.). En el caso de Iluro, los ejemplos son relativamente numerosos y parecen indicar una práctica generalizada y consciente que va encaminada al mantenimiento de algunos servicios. Se pueden mencionar la reutilización de sillares con inscripciones como base de una gran columna que se levantó en la zona del forum, la utilización de otras inscripciones en la construcción de muros (vid. supra) o la reparación ya indicada de un tramo de la alcantarilla central del cardo maximus, para la que se usaron cornisas de mármol, una acrótera de arenisca e inscripciones funerarias (cerdà $e t$ al., 1997, vol. I: 111 y figuras de las págs. 176, 244 y 247-248; Cerdà et al., 1997, vol. II: 221ss.). Las actuaciones afectaron a los edificios públicos, a juzgar por las dimensiones de algunas piezas recuperadas y por la presencia de inscripciones de carácter cívico evidente, así como a la arquitectura funeraria. Se trata de dos ámbitos especialmente ligados a la expresión formal de la vida cívica y social durante el alto imperio y que, en consecuencia, fueron afectados directamente por los cambios socioeconómicos y culturales. Aunque son de pequeña entidad, los expolios detectados indican el dinamismo del hábitat, ya que responden a una estrategia continua y selectiva para aprovechar los recursos que aportaba la antigua ciudad bajo la forma de reutilización o reciclaje (cf. Remolà, 2000b).

Por otro lado, estos procesos de expolio presentan rasgos particulares y responden a una dinámica que no se limita a la antigüedad tardía. Su interpretación, por tanto, es compleja. La transformación de los espacios y edificios de la ciudad se inicia ya a finales del siglo I d.C. y será muy intensa durante el siglo II, al igual que en ciudades cercanas (Baetulo). También es en el siglo II cuando se detectan evidencias de abandono de instalaciones domésticas y productivas, al tiempo que se construyen otras, y se inicia el expolio selectivo de grandes residencias y monumentos funerarios. El registro estratigráfico no permite establecer claramente si los lugares expoliados fueron abandonados totalmente o reconstruidos y ocupados por un hábitat más modesto, combinado o no con actividades productivas. Estas reocupaciones se documentan en muchas ciudades hispanas a partir de los siglos IV-V, cuando se restructuran domus e insulae (Gurt, 2000-2001: 458). Pero en Iluro los restos de las domus conocidas ya no eran visibles en los siglos V-VI y la nueva ocupación no puede considerarse, en sentido estricto, una continuidad o reconstruc- ción del hábitat; entendiendo como tal un proceso relacionado con el uso y adaptación conscientes de unos edificios y una organización espacial prexistentes. Por el contrario, los rasgos que definen esta ocupación muestran una ruptura evidente.

La relación entre procesos de abandono, expolio y restructuración del espacio urbano presenta rasgos mal definidos en el caso de Iluro. La ciudad inició su transformación muy pronto; si puede hablarse de inicio en el caso de un fenómeno que responde a una dinámica normal en cualquier hábitat. El expolio, en este contexto, adoptó formas y significados muy diversos, ya que era tanto una solución privada (lo que explicaría buena parte de las actuaciones del siglo II) como una respuesta a la necesidad de mantener las infraestructuras públicas; caso del alcantarillado o del gran edificio del forum, entre los siglos III y IV. En Iluro, en realidad, los abandonos y expolios documentados se relacionan básicamente con el hábitat de los siglos II a IV y con la continuidad de unos servicios y una vida colectiva de tipo urbano, a pesar de su modestia, hasta finales del siglo IV-inicios del V. Por su parte, el hábitat de los siglos VI y VII ocupa con total libertad buena parte del antiguo espacio urbano y no se aprecian actuaciones para mantener infraestructuras o utilizar construcciones todavía visibles; de la misma forma que no se mantuvo la estructura viaria. Tampoco es casual que las evidencias relacionadas con la recuperación intencional y regular de ciertos tipos de material antiguo, tales como sillares, tegulae o ladrillos, sean escasas. El desarrollo de actividades específicas de obtención y uso de materiales, en esta fase, se relaciona directamente con unas necesidades constructivas modestas, que indican, a su vez, la existencia de nuevas condiciones de vida y nuevas exigencias respecto a la comunidad del alto imperio.

Otro rasgo característico de la organización del espacio y el hábitat en la Iluro de época tardía es la proliferación de fosas y su uso posterior como vertederos (Cela, Revilla, 2004: 169ss.). Las fosas son de dimensiones considerables y perforan los estratos republicanos y del alto imperio hasta alcanzar el terreno natural (fig. 5). Estas excavaciones afectaron indiferentemente lo que habían sido edificios y espacios públicos y privados. Con frecuencia, su perímetro sigue la alineación de las cimentaciones de los antiguos edificios, que ya no eran visibles, y las desmontan parcialmente, manteniendo una parte de la estructura como límite de la fosa ( $c f$. Demians D'archimbaud, 1994: 33). Por en contrario, algunas fosas profundizan en el terreno natural sin afectar estructuras arquitectónicas. En ocasiones, se aprecia una conexión física entre dos fosas aparentemente diferentes, pero que presentan una sedimentación similar. Esta situación parece depender de la función primaria de las fosas y de las condiciones de frecuentación posterior de cada lugar; se trata probablemente de ampliaciones 

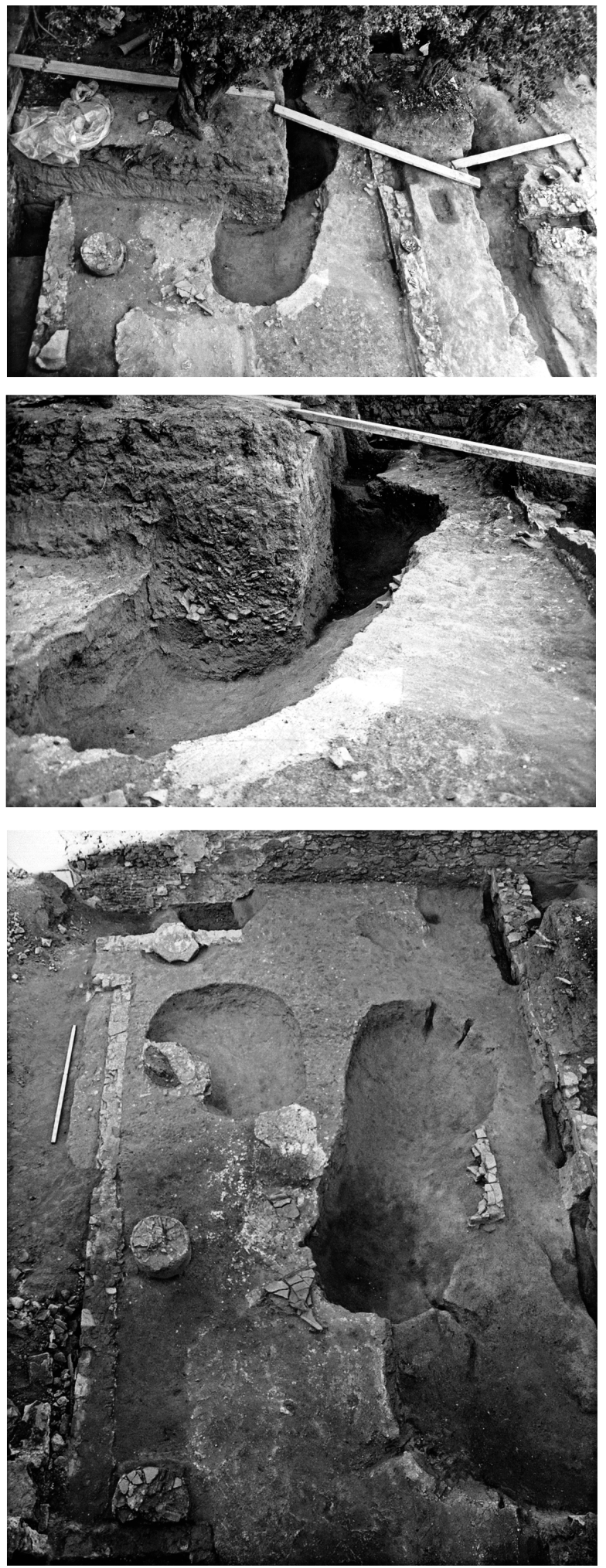

Figura 5. Imagenes de las fosas tardías excavadas en el peristilo de la antigua Domus de la Palma. 
de una primera fosa que se realizaron antes de que ésta empezara a acumular vertidos ${ }^{41}$.

Las fosas no pueden considerarse estructuras de almacenamiento, ya que se distinguen claramente de los silos, y tampoco de hábitat, pues sus dimensiones, límites y profundidad son muy irregulares. En contra de esta posibilidad, también hay que mencionar la ausencia de elementos arquitectónicos relacionados con la delimitación, cubrición o creación de accesos, así como de instalaciones propias de la vida doméstica ${ }^{42}$. Tampoco pueden considerarse excavaciones realizadas con el objetivo de recuperar material constructivo (con una posible excepción), ya que su trazado es errático y cuando quedan a la vista las cimentaciones antiguas no se procede a su expolio, como parecería lógico. Finalmente, debe excluirse la intención de crear vertederos en la mayoría de los casos. Todas las fosas seccionan la estratigrafía de la ciudad imperial por completo y la excavación siempre es de gran profundidad, lo que parece un esfuerzo excesivo para acumular basuras. Las ampliaciones posteriores de algunas fosas aportan otro argumento en contra: en todos los casos, la ampliación se realizo cuando todavía no se habían realizado vertidos en las depresiones creadas; la nueva excavación respondería, por tanto, a una intención diferente a la de crear un depósito. El hecho de que tanto las fosas como los silos acabaran cubiertos por residuos domésticos resulta de un uso secundario que se relaciona con las necesidades de un hábitat cercano.

Seguramente, la excavación de estas fosas responde a la búsqueda del terreno natural para la extracción de materia prima para la construcción. El suelo geológico sobre el que se asienta la ciudad está formado por un sedimento arenoso y arcilloso, muy compacto, que era más apropiado para la elaboración de estructuras en tapial o adobes que las arenas procedentes de los torrentes o la playa cercanas. Una hipótesis similar ha sido propuesta para explicar la formación de fosas de forma irregular y grandes dimensiones en el oppidum de SaintBlaise (Demians D'archimbaud, 1994: 47) ${ }^{43}$.

Los depósitos que rellenan las fosas y los silos están formados por tierras, materia orgánica y gran cantidad

\footnotetext{
${ }^{41}$ Así, tanto en La Solana como en Saint-Blaise se identifican ampliaciones y fosas posteriores con estratificaciones diferentes: Morer, Rigo, Barrasetas, 1997: 92; Demians D'archimbaud, 1994: 32 y 49 .

${ }^{42}$ Como los hogares y pavimentos, que aparecen, por ejemplo, en La Solana: Morer, Rigo, Barrasetas, 1997; criterios de identificación en Vigil, 2000: 223-224.

${ }^{43}$ Morer, Rigo, Barrasetas, 1997: 93, aluden a la extracción de arcillas, en La Solana, que no podrían ser utilizadas en la elaboración de cerámica por su elevado contenido calcáreo; la propuesta de los excavadores es que quizá fueron utilizadas en la construcción de las modestas estructuras del lugar.
}

de materiales. Sus características sugieren un ritmo de formación rapido. Los materiales corresponden a residuos de actividades domésticas. En este conjunto se pueden distinguir elementos y productos asociados a la manipulación directa y consumo de alimentos (materia orgánica, cerámicas de mesa y de cocina), recipientes de almacenamiento y transporte, objetos de ajuar doméstico (vidrios, lucernas) y elementos constructivos (madera, piedra, fragmentos de opus signinum, estatuaria, tegulae e imbrex). El material residual es abundante; pero también se han recogido recipientes de vajilla y ánforas bien conservados y sin señal de reparación, depositados inmediatamente después de su uso. Con las precauciones que impone la elevada residualidad, los depósitos aportan una imagen fiable del consumo local de productos alimentarios y de vajillas, así como de las regiones proveedoras, en el momento de su formación ${ }^{44}$.

En los depósitos se han recogido numerosos restos de fauna terrestre y marina, y también son frecuentes las concentraciones de carbones y ceniza. Aunque no se han identificados niveles de combustión en los vertidos, y mucho menos hogares, la presencia de tales concentraciones sugiere la existencia de procesos de incineración de residuos; por lo menos parcial ( $c f$. Gurt, 2000-2001: $455)$. Con todo, es posible que en ocasiones estas concentraciones de material no correspondan a una combustión in situ, sino a la deposición secundaria de restos quemados en otro lugar. Los depósitos también han aportado escorias de hierro que podrían considerarse residuos de producción y que indicarían una actividad artesanal. No se puede precisar, sin embargo, la entidad de esta producción, el grado de especialización del trabajo y la orientación. Este tipo de evidencias de actividad metalúrgica se detecta en los vertederos domésticos de otros lugares, como Saint-Blaise (Demians D'archimbaud, 1994: 28-29). Por el contrario, la limitada presencia de elementos metálicos trabajados indica seguramente un reciclaje selectivo e intenso del utillaje doméstico. En este mismo sentido debe interpretarse el hallazgo de fragmentos de una estatua de Venus, posiblemente de un taller oriental, en una fosa excavada en un sector de las termas de Iluro: estos fragmentos debieron destinarse a la elaboración de cal. Se trata, en definitiva, de vertederos mixtos y no especializados, que aprovechan la presencia de excavaciones (fosas) y estructuras abandonadas (silos) para un nuevo uso.

La datación del momento de excavación y de reutilización de los silos y de las fosas es difícil (Cela, Revilla, 2004: 171ss.). En primer lugar, porque se trata de accio-

\footnotetext{
${ }^{44}$ Interpretación de la evidencia disponible en Cela, Revilla, 2004; para vertederos tardíos: Gurt, 2000-2001: 455ss.; Remolà, 2000a: 31; id., 2000b; Murialdo, Bonora, 2001: 177, señalan la presencia de vertederos dentro de viviendas.
} 
nes con un fin diferente y porque el propio hecho de la excavación raramente deja evidencias, aunque debía tratarse de procesos rápidos. En el segundo caso (la reutilización), porque la naturaleza doméstica de los depósitos hace muy complicado determinar el ritmo de formación. Las relaciones estratigráficas que ha sido posible establecer indican que la mayoría de silos serían anteriores a las fosas. Por otro lado, algunos estratos afectados por los silos permiten datar la excavación de los mismos con posterioridad al segundo-tercer cuarto del siglo IV; en un caso, a mediados-segunda mitad del V. El periodo de uso de los silos parece situarse, por consiguiente, entre los siglos IV y V. Su abandono y relleno ocupa el siglo VI; en algunos casos, de forma simultánea a la colmatación de fosas cercanas e indicando una situación común en la que unos y otras sirvieron de vertedero. En lo que respecta a las fosas, las características de los depósitos indican un proceso de vertido relativamente rápido y continuado hasta ocupar el espacio disponible. No se han identificado niveles de sedimentación natural o diferencias en la estratigrafía que indiquen momentos de abandono seguidos de una nueva frecuentación. La formación de los vertederos excavados en su totalidad se sitúa hacia finales del siglo VI y quizá podría llegar hasta inicios del VII. Otros vertidos identificados, ya sea por problemas derivados de una excavación parcial, o por el escaso material que aportan, se sitúan grosso modo en el siglo VI. Algunos de ellos quizá podrían datarse a mediados-segunda mitad del VI, ya que parecen mostrar una facies cerámica diferente respecto tanto a los grandes estratos de nivelación de finales del siglo V-inicios del VI como a los depósitos claramente más tardíos.

El contenido, el proceso de formación y la distribución de estas fosas en el espacio que había correspondido a la antigua Iluro constituyen una fuente de información de primer orden para conocer la cultura material y las características del poblamiento entre los siglos VI y VII y, a partir de ello, intentar definir la naturaleza del nuevo hábitat.

Se desconocen los procedimientos relacionados con la gestión de los residuos urbanos en Iluro en época tardorrepublicana y durante el alto imperio; con excepción del sistema típico de alcantarillado público y doméstico. Este desconocimiento es el resultado de la falta de excavaciones en la periferia urbana, donde debían estar situados los vertederos de la ciudad. Se han identificado algunos depósitos de época tardorrepublicana dentro de los límites urbanos, pero siempre corresponden a vertidos específicos, dominados por los materiales constructivos o a restos de producción cerámica, cuyo fin es preparar el terreno para alzar nuevas construcciones y que inutilizan estructuras de época fundacional. Este tipo de actuaciones parecen más intensas en época de Augusto, en relación con lo que parece un aumento de la actividad constructiva (vid. supra). Recientemente, se han identificado en el interior de la ciudad estratos de nivelación del siglo II d.C. que parecen relacionados con la ocupación de los sectores norte y este (descripción en Cela, Revilla, 2004: 415). A pesar de la falta de datos, parece que la ciudad republicana y del alto imperio supo organizar la gestión de sus residuos y situarlos al margen de los espacios ocupados; otra cuestión es si los vertidos se situaban en la periferia o en el exterior del recinto urbano. Otras situaciones, como los depósitos de material constructivo dentro de la ciudad, indican la misma capacidad de gestión, ya que se relacionan con actuaciones urbanísticas ${ }^{45}$.

La situación cambia radicalmente durante el siglo VI, momento en que se generaliza dentro del antiguo espacio urbano la práctica de utilizar fosas como vertederos. Las evidencias se concentran en los sectores oriental y central de la ciudad, superponíendose a las anteriores domus y edificios y espacios públicos (por ejemplo, las termas); si bien, como se ha indicado, ninguna de estas estructuras parece ya visible en este momento. Todos los depósitos se realizan en fosas excavadas con otra intención, pero su dispersión no es casual. La composición, dimensiones y ritmo de los vertidos sugiere un funcionamiento en la esfera doméstica y un carácter privado. Y aunque casi no se dispone de evidencias constructivas y las que se conocen no se pueden poner en relación con los vertidos, parece claro que existe en Iluro la misma asociación entre actividades domésticas, producción y vertederos que caracteriza a otros nucleos urbanos y rurales de época tardía

La distribución de los depósitos y la más que probable relación con el hábitat parecen responder a un modelo de ocupación dispersa, de poca densidad y que no se integra en una trama ortogonal. Cada uno de los lugares indicados por su presencia correspondería a una unidad o un pequeño grupo de unidades domésticas que funcionarían de forma autónoma en lo que respecta a sus procesos de trabajo y la gestión de sus residuos; a diferencia de la situación que presentaba la ciudad original, que controlaba tanto las actividades económicas como los vertidos, trasladados al exterior. Esto no excluye alguna forma de control comunitario, que podría incentivar, por ejemplo, el uso de lugares abiertos y desocupados; dicho de otro modo, lugares periféricos al hábitat, aunque no muy alejados, donde sería posible depositar los residuos y realizar algunas operaciones relacionadas con su tratamiento; por ejemplo, la incineración de materia orgánica. La colmatación de fosas permitiría, además, eliminar desniveles del terreno para facilitar la circulación o la reocupación (evidencias en Gurt, 2000-2001: 456). En términos econó-

\footnotetext{
45 Para el uso de la periferia de las ciudades romanas en la gestión de los residuos y las actuaciones a gran escala en estas zonas: Gelichi 2000; Remolà 2000b.
} 
micos, los vertederos indican la existencia de estrategias de diversificación que combinan agricultura, ganadería y actividades artesanales. Estas actividades se centran en la fabricación y reparación de utillaje relacionado con la producción y las necesidades cotidianas de transformación de alimento, la construcción etc., pero también incluyen el reciclaje y parecen desarrollarse en un marco de pequeñas unidades productivas autónomas y circuitos de intercambio restringidos (por el tipo de productos) y de limitada entidad (por la cantidad y valor de los mismos).

Los vertederos también indican un cambio importante en las formas de vida en otro sentido: la ruralización del antiguo espacio urbano. La escasa densidad y la distribución irregular de un hábitat formado por la combinación de viviendas, huertos y zonas vacías caracterizan un paisaje en que el aglomerado de población debía extenderse sin solución de continuidad más allá del antiguo recinto urbano, hasta confundirse con el campo inmediato. Esta confusión sería facilitada por la presencia de pequeñas áreas cementeriales. La posterior villa de Mataró mantuvo esta combinación de zonas edificadas, patios y huertos hasta el siglo XVI, como muestra un censo de 1596-1601 (Cerdà et al., 1997, vol. I: 272, fig. 2). Hay que considerar, en este mismo contexto, la ausencia de ciertas estructuras e instalaciones identificadas en otros asentamientos tardíos: recintos para ganado, espacios de trabajo excavados en el terreno y delimitados por muretes, prensas, etc. Todos ellos se documentan, por ejemplo, en La Solana. La falta de excavaciones en extensión en el núcleo histórico de Mataró ha impedido recuperar este tipo de evidencia que, además, es difícil de identificar en el registro estratigráfico.

La vinculación hábitat-vertederos responde, en resumen, a una situación nueva en términos de gestión de residuos: una gestión dinámica y una relación diferente con este tipo de materiales. Su composición aporta, a la vez, una imagen fiable, aunque limitada, de las condiciones de producción, circulación y consumo de algunos productos básicos en el periodo considerado y de sus relaciones con el hábitat. La interpretación de esta evidencia es difícil, ya que la formación de los depósitos puede responder a factores muy diversos. En este mismo contexto, es igualmente peligroso utilizar directamente esta evidencia para evaluar la riqueza o pobreza global de la comunidad o para calificar el periodo. La composición de los vertidos indica, ante todo, situaciones cotidianas; en segundo lugar, unas estrategias adaptadas a un contexto definido por la autonomía y la diversificación productiva, la regionalización de los intercambios y la transformación de los modelos de comportamiento y los valores. Sólo en esta perspectiva es correcto intentar precisar su valor como indicador cultural.
¿Cómo se puede valorar el conjunto de transformaciones que afectan al antiguo espacio urbano y a las actividades y funciones que se concentran en el lugar? Aunque no es posible definir su ritmo y las relaciones precisas entre los diversos fenómenos identificados, es evidente que todos ellos se integran en un proceso global y que este proceso tiene un significado claro: el cambio en las formas de vida.

La evidencia arqueológica indica la existencia de un hábitat estable y bien organizado, vinculado a la tradición cultural romana en términos materiales, como muestran la tecnología y las herramientas relacionadas con la vida cotidiana aportados por los circuitos de intercambio; y también vinculado en lo que respecta a los aspectos ideológicos, ya que algunos espacios de la antigua ciudad siguieron reservándose para funciones comunitarias. En este sentido, se puede hablar de continuidad cultural. A la vez, esta continuidad se acompaña de transformaciones profundas de la arquitectura, el espacio urbano y las actividades; todas a pequeña escala, sin una planificación global, pero desarrolladas de forma continuada hasta crear un nuevo paisaje. Este proceso global es un buen indicador de la vitalidad de la comunidad, con independencia de sus dimensiones, así como de la existencia de unas jerarquías sociales bien definidas. Por ahora, no es posible precisar hasta qué punto los ritmos de evolución de los espacios públicos y privados coincidieron o se diferenciaron. Tampoco puede determinarse el grado de continuidad en el uso de algunos sectores y el significado de ciertos fenómenos. En apariencia, la distinción entre la zona alta de la antigua ciudad, donde se concentran funciones relacionadas con la vida colectiva, y la periferia, ocupada por el hábitat privado, reproduce un principio originado en la fundación republicana y que se reafirma en el municipium. Pero la continuidad de funciones sólo parece evidente en la zona alta. La concentración aquí de las actividades relacionadas, primero con la economía, y después con la religión, obligaría a situar el hábitat en la periferia; con más razón cuando se trata de edificaciones dispersas, acompañadas de vertederos y actividades productivas, que precisaban superficies amplias. La dispersión del hábitat y la creación de nuevos ejes de circulación indican, más allá de las coincidencias, la ruptura con la anterior estructura urbanística y la nueva organización espacial.

La secuencia estratigráfica de Mataró se interrumpe a partir de finales del siglo VI-inicios del VII. Las evidencias arqueológicas de un hábitat posterior se datan en el siglo XII, pero no se hacen más consistentes hasta el XIV (Cerdà et al., 1997, vol. I: 270ss.; Cerdà, Gurri, 2000). Los datos de este siglo indican claramente una ocupación organizada según patrones diferentes al urbanismo de la ciudad romana y que 


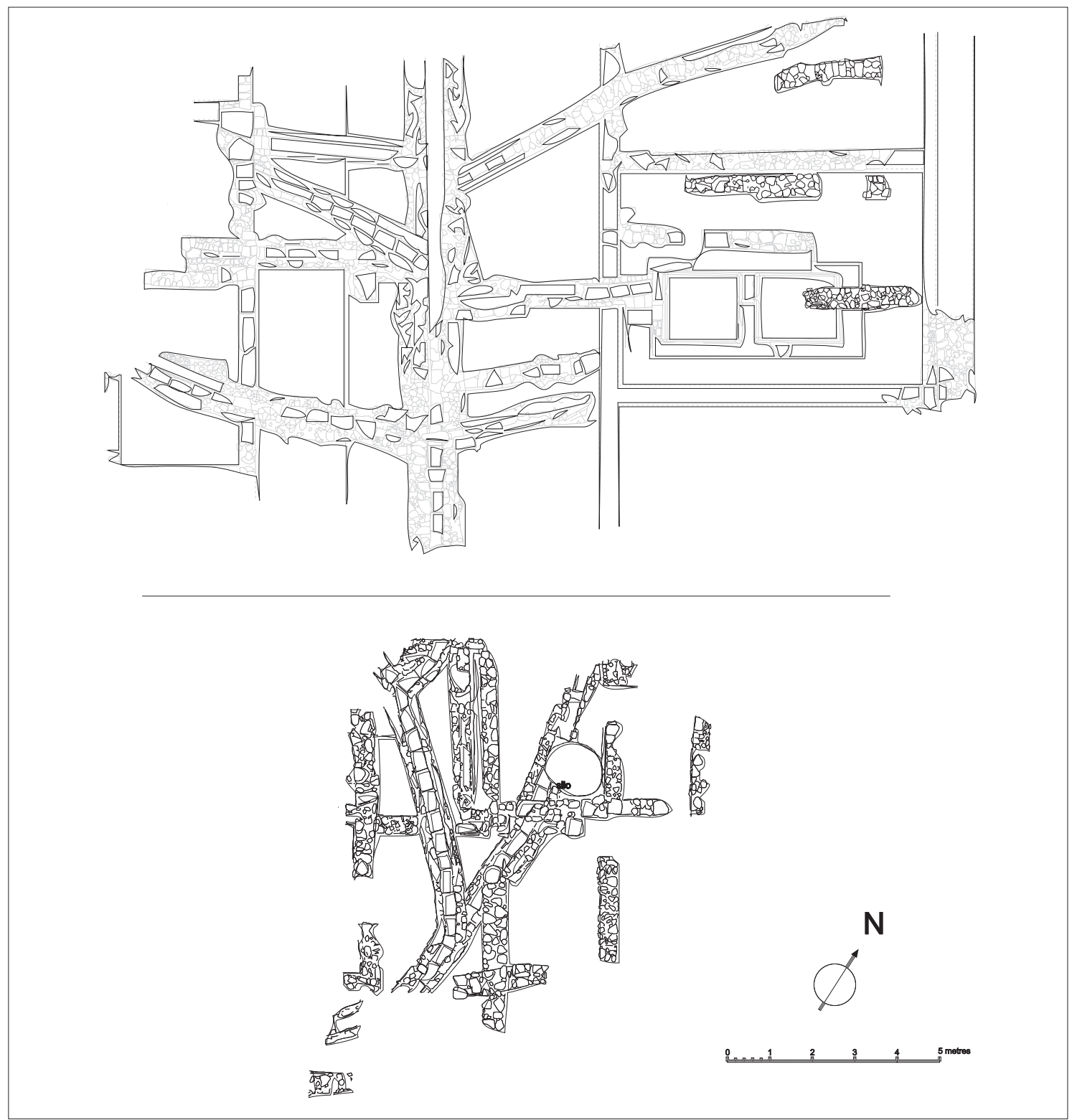

Figura 6. Restos arquitectónicos del siglo VI d.C. documentados en las proximidades del antiguo cardo maximus. En este momento, las estructuras de los siglos I a.C.-V d.C. (en trama de gris claro) estan totalmente amortizadas.

corresponde a otra situación socioeconómica y jurídica (Cuadrada, 1988a; Cerdà, Gurri 2000; Llovet 2000: 35ss.). Sin embargo, la documentación escrita indica algún tipo de ocupación articulada en una parrochia a inicios del siglo XI; concretamente, en el año 1008, aunque también hay una referencia del año 946 (Cuadrada, 1988b; Llovet, 2000: 35). Esta desconexión entre arqueología y textos, que crea un aparente vacio histórico, se constata en otras ciudades (Macias, 2000; Remolà, 2000a: 26ss. y 304). Por lo que respec- ta al espacio del actual casco histórico de la ciudad, este vacío documental se puede explicar por la destrucción de la estratigrafía resultado de la ocupación bajomedieval y moderna. Pero esta explicación es insuficiente, ya que no se puede pensar en un proceso de eliminación sistemática del hábitat altomedieval que habría dejado, por el contrario, las evidencias de la antigüedad tardía. Por no hablar de la documentación escrita de los siglos X-XI que atestigua una ocupación. 
La explicación de una supuesta ausencia de ocupación en los siglos de la alta edad media debe buscarse, en parte, en la generalización de nuevas condiciones de vida y de trabajo, caracterizadas por la modestia material, poco definidas en términos de registro arqueológico y que se proyectan sobre el territorio de forma diferente a como había hecho la cultura romana. Este proceso se debía producir durante el siglo VI y se afirmaría desde finales del VI-inicios del VII. La importancia de la fase de ocupación representada por los depósitos de las fosas reside en que indica una situación definida, en primer lugar, por la existencia de pequeñas aglomeraciones rurales que agrupan un reducido conjunto de unidades domésticas, cada una de las cuales concentra las actividades y espacios necesarios para asegurar el funcionamiento autónomo de un grupo familiar (residencia, huerto, vertederos). Esta situación prescinde de las tramas espaciales regulares. En segundo lugar, por una economía de base agrícola, pero capaz de cierta diversificación; autosuficiente, pero que mantiene su capacidad de acceso a los productos de importación (básicamente, alimentarios). Esta forma de hábitat, entendida en términos estrictamente materiales, ya que es imposible abordar en el estado actual de conocimiento los aspectos ideológicos y de estructura social, caracterizaría la ocupación del espacio de la antigua Iluro hasta un momento indeterminado de la alta Edad Media.

Las actividades domésticas y productivas de este tipo de hábitat también son difíciles de registrar porque utilizan materiales frágiles y una tecnología de poca complejidad (fig. 6); baste pensar en la inexistencia de construcciones domésticas que utilicen la piedra, que es sustituida por el uso del tapial y la madera, en la reaparición de la práctica del almacenamiento en silos o en la multiplicación de estructuras excavadas en el terreno (Morer, Rigo, Barrasetas, 1997). Estas expresiones materiales no pueden ser valoradas sencillamente como expresión de una decadencia. Siguiendo esta perspectiva, sería imposible apreciar la especificidad de este periodo. El hábitat de los siglos VI y VII indica, por el contrario, la adaptación de una población a las nuevas condiciones sociales, económicas y culturales surgidas en el occidente europeo, utilizando estrategias complementarias: la diversificación y la autosuficiencia.

\section{CONCLUSIONES}

El registro estratigráfico muestra cambios muy importantes en la arquitectura y la organización del hábitat en el espacio ocupado por la antigua Iluro desde finales del siglo $\mathrm{V}$ hasta un momento impreciso de los siglos VI o VII. Estos cambios deben ser considerados en un marco más amplio para no interpretarlos como el reflejo de un proceso de decadencia y, en relación con ello, reducir la historia de la ciudad imperial a la descripción de una crisis anunciada e ireversible. Como se ha indicado, Iluro experimentó continuas transformaciones en su urbanismo y sus edificios desde el momento de su fundación. Los cambios fueron especialmente intensos a partir de finales del siglo I y durante el II. A pesar de su entidad, tales cambios no parecen alterar la fisonomía general de la ciudad. Y de hecho, todavía se detectan obras de mantenimiento hasta finales del siglo IV.

Este conjunto de modificaciones de la arquitectura y el urbanismo muestran claramente el proceso de adaptación de una comunidad a condiciones históricas en continua transformación y se deben valorar como expresión directa de su dinamismo. Otro problema importante es hasta qué punto los esfuerzos para mantener en funcionamiento una parte de la estructura urbana original permiten definir a la Iluro del siglo IV como una ciudad. ¿Suponen estos esfuerzos la perduración de los antiguos modelos de comportamiento cívico, y de la ideología correspondiente, aunque sea de forma modesta?. Los paralelos que aportan las pequeñas ciudades del nordeste de Hispania Tarraconensis (Emporiae, Baetulo, Iesso, Aeso, Dertosa) son poco esclarecedores, ya que las situaciones son muy diversas. Un hecho significativo es el final de las evidencias relacionadas de forma indiscutible con programas arquitectónicos y epigráficos, en estas pequeñas ciudades, entre los siglos II y III. Esta ausencia, más allá de la existencia de reformas puntuales y la continuidad de ciertas construcciones, indica claramente los límites de la actuación y de la conciencia cívica de una comunidad. En el caso de Iluro, con todo, la preocupación por mantener la red viaria principal y algunas infraestructuras parece mostrar todavía el funcionamiento de mecanismos de control de la vida colectiva entre los siglos II y IV.

En un momento que hay que situar en la segunda mitad del siglo V e inicios del VI se produce un cambio importante en el paisaje de la antigua ciudad. La primera conclusión que se desprende del estudio de la documentación es la desaparición prácticamente total de la estructura urbanística anterior. Los rasgos que definen la nueva organización del espacio no se pueden precisar con claridad. El fenómeno más evidente es la proximidad de las actividades y las funciones a diversos niveles: hábitat y uso funerario, dentro del espacio urbano considerado globalmente; hábitat y producción, así como coexistencia de diversas actividades económicas, a escala domestica, a juzgar por el contenido de las fosas. Esta proximidad, que responde a nuevos comportamientos y modos de organizar la vida cotidiana, no implica, en absoluto, una confusión 
de las actividades. Hábitat y cementerio (o cementerios) ocupan espacios separados, de la misma forma que el cementerio y los silos de la Plaça de Santa Maria corresponden a momentos diferentes. En relación con estos cambios se reorganizan los ejes viarios, que ya no se distribuyen según una retícula regular preconstituida, si no en función de la multiplicación de zonas ocupadas y de lugares clave que resulta de la nueva distribución del hábitat, las actividades y los centros de poder. La arqueología indica que la nueva ocupación se concentra en unas áreas concretas. Este hecho se relaciona con la existencia de un espacio de vida colectiva que concentra, sucesivamente, actividades materiales (almacenamiento en silos) y función ideológica. También desaparece ahora la distinción entre espacio urbano, entendido como superficie edificada y cerrada por murallas. y territorio. En este nuevo escenario no hay rastro de la antigua ideología cívica o de sus expresiones religiosas. Por el contrario, las escasas evidencias disponibles muestran un proceso de cristianización avanzado y que parece actuar como referente ideológico principal, expresándose a través del culto, un aspecto, este, pendiente de confirmación arqueológica, y una práctica funeraria institucionalizada. Con todo, no se puede obviar la función económica del asentamiento, materializada en un campo de silos que almacena parte del excedente agrícola del territorio.

El impacto sobre el territorio de la aglomeración de los siglos VI-VII reside en la combinación de algunas funciones: residencia, actividades productivas diversificadas y presencia de lo que podría denominarse servicios ideológicos (un lugar de culto y una o más zonas funerarias). Estas funciones afectan a un ámbito rural limitado, en el cual parecen constituirse otros centros de población que utilizan mecanismos ideológicos y sociales similares, como muestran la presencia de necrópolis importantes (Ca la Madrona) y la distribución de la epigrafía funeraria cristiana. El nuevo paisaje rural se define, por tanto, por una estructura policéntrica, con asentamientos de pequeño tamaño, y por una mayor permeabilidad entre campo y núcleos de población; una situación totalmente diferente del control exclusivo, administrativo, social y económico, que había ejercido el municipio imperial sobre el territorio. Solo en este sentido y en este contexto es aceptable utilizar el término ruralización para definir el alcance y el significado de los cambios que afectan a tantas pequeñas ciudades en la antigüedad tardía. En este momento, sin embargo, es imposible definir con precisión los mecanismos y las relaciones sociales que permitieron la concentración de las funciones indicadas en este y otros lugares, y mediante las cuales se organizó la explotación del territorio.
Es innecesario decir que las evidencias disponibles, de naturaleza básicamente arqueológica, son insuficientes para abordar con garantías un fenómeno de cambio cultural que supera los límites de una pequeña comunidad. Así, quedan al margen de este estudio, por fuerza, aspectos muy importantes como la estructura social o las mentalidades, que se insinúan detrás de las prácticas funerarias o de la variedad de los repertorios cerámicos consumidos in situ, pero que no pueden apreciarse en toda su complejidad. Con todo, las evidencias materiales aportan una prueba indiscutible de la magnitud de los cambios que afectan a la vida cotidiana y la economía. Es por ello que este estudio ilustra perfectamente los problemas a que se enfrenta la traducción, en términos socioeconómicos y culturales, de los datos que incluye el registro arqueológico.

\section{BIBLIOGRAFÍA}

ALFÖLDY, G., 1985: Hispanien und das römische Heer. Bemerkungen zu Patrick Le Roux: L'armée romaine et l'organisation des provinces ibériques d'Auguste à l'invasion de 409. Gerion, 3, 379-410 (=Römische Heeresgeschichte. Amsterdam, 1987, 482-513).

AQUILUÉ, X., 1987: Las cerámicas africanas de la ciudad romana de Betulo (Hispania Tarraconensis), BAR Int. Series 337. Oxford.

ARRIBAS, A.; TARRADELL, M. 1987: El foro de Pollentia. Noticia de las primeras investigaciones. Los foros romanos en las provincias occidentales (València, 1986). Madrid, 121-136.

ARXÉ et al., 1986: ARXÉ, J.; BACARIA, A.; BASTIT, C.; CABALLERO, M.; PRATDESABA, P., Ultimes intervencions a Iluro (Mataró, El maresme), Tribuna d'Arqueologia 1984-1985, Barcelona, 73-82.

BARRAL, X., 1982: Transformacions de la topografia urbana a l'Hispània cristiana durant l'Antiguitat Tardana, II Reunió d'Arqueologia Paleocristiana Hispànica (Montserrat-Barcelona, 1978), Barcelona, 105-132.

BONAMUSA, J., 1972: La necròpolis iluronesa de La Riera actualitzada arran de les últimes troballes, Información Arqueológica, 8-9, 37-42.

BROGIOLO, G. P., 1989: Brescia: Building transformations in a Lombard city. K. Randsborg (ed.), The Birth of Europe. Archaeology and Social Development in the First Millenium A.D. Analecta Romana Instituti Danici Suppl. XVI, Roma, 156-165.

BROGIOLO, G. P.; WARD-PERKINS, B., eds., 1999: The idea and Ideal of the Town between Late Antiquity and the Early Middle Ages, LeidenBoston-Köln. 
BROGIOLO, G. P.; GAUTHIER, N.; CHRISTIE, N., eds., 2000:. Towns and their Territories between Late Antiquity and the Early Middle Ages, LeidenBoston-Köln.

CANTINO-WATAGHIN, G., 1999: The Ideology of urban Burials. G. P. Brogiolo, B. Ward-Perkins (eds.), The Idea and Ideal of the Town between Late Antiquity and the Early Middle Ages, LeidenBoston-Köln. 147-180.

CASTANYER et al., 1993: CASTANYER, P.; SANMARTÍ, E.; SANTOS, M.; TREMOLEDA, J.; BENET, C.; CARRETÉ, J. M ${ }^{\mathrm{a}}$; FABREGA, X.; REMOLÀ, J. A.; ROCOS, X., L'excavació del kardo B. Noves aportacions sobre l'abandonament de la ciutat romana d'Empúries, Cypsela, X, 159194.

CASTELLANOS, S., 2000: Los lugares sagrados urbanos en las transformaciones del occidente tardoantiguo. Lo sagrado en el proceso de municipalización del occidente latino. Iberia, 3, 129-149.

CELA, X.; REVILLA, V., 1999: La topografía del artesanado urbano en el litoral de Hispania Tarraconensis: el caso de Iluro, MBAH, XVIII, 24-44.

CELA, X.; REVILlA, V., 2004: La transició del municipium d'Iluro a Alarona (Mataró). Cultura material $i$ transformacions d'un espia urbà entre els segles $V i$ VII dC. Laietània 15. Volumen monográfico. Mataró.

CELA, X.; GARCIA ROSELLO, J.; PERA, J., 2003: Fem Arqueologia descobrim la Ciutat. Catálogo Exposición. Mataró

CERDÀ et al., 1997: CERDÀ, J. A.; GARCÍA ROSELLO, J.; MARTÍ, C.; PERA, J.; PUJOL, J.; REVILLA, V., El cardo maximus de la ciutat romana d'Iluro (Hispania Tarraconesis), Laietània 10. Volumen monográfico. Mataró.

CERDÀ, J. A.; GURRI, E., 2000: Continuïtat i canvis a la vila d'Alarona (Mataró) a l'Alta Edat Mitjana. Actes del ler Congrés d'Arqueologia medieval $i$ moderna de Catalunya (Novembre de 1998). ACRAM, Barcelona, 100-113.

CLARIANA, J.-F., 1994a: Iluro ciutat romana. Col.lecció Sal.lusti 1, Mataró.

CLARIANA, J.-F., 1994b: Apunts sobre la Iluro romana, Actes de la X Sessió d'estudis Mataronins. Museu Arxiu de Santa Maria, Mataró, 47-74.

CLARIANA et al.. 1993: CLARIANA, J.-F.; CLEMENTE, M.; JÁRREGA, R.; JUHE, E., L'arquitectura domèstica de la romana Iluro, estat de la quesito, Actes de la IX Sessió d'Estudis Mataronins. Museu Arxiu de Santa Maria, Mataró, 39-60.

CUADRADA, C., 1988a: El Maresme Medieval: Hàbitat, Economia $i$ Societat. Segles X-XIV. Mataró
CUADRADA, C., 1988b: Civitas Fracta, tornem-hi a pensar, Civitas Fracta II, Mataró, 9-14.

DEMIANS D'ARCHIMBAUD, G., (dir.), 1994: L'oppidum de Saint-Blaise du Ve au VIIe s. (Bouches-du-Rhône). Documents d'Archéologie Française 45. Paris.

DÍAZ, P., 2000: City and Territory in Hispania in Late Antiquity. G. P. Brogiolo, N. Gauthier, N. Christie (eds.), Towns and their Territories Between Late Antiquity and the Early Middle Ages, LeidenBoston-Köln, 3-35.

ENRICH, J.; ENRICH, J., 1995: Vilaclara de Castellfollit del Boix. Un assentament rural de l'antiguitt tardana. Igualada.

FUENTES, A., 1999: Aproximación a la ciudad hispana de los siglos IV y V d.C., L. A. García Moreno, S. Rascon (eds.). Complutum y las ciudades hispanas en la Antigüedad tardía (Alcalá de Henares, 1996), Alcalá de Henares, 25-50

GARCÍA MORENO, L. A. ,1977-1978: La cristianización de la topografía de las ciudades en la Península Ibérica durante la Antigüedad Tardía, AEspA, 50-51, 311-323.

GARCÍA ROSELLÓ, J.; CERDÀ, J. A., 1990: Una necrópoli tardo-romana a Ca la Madrona (Mataró, el Maresme), Actes de la VI Sessió d'Estudis Mataronins, Mataró, 7-22.

GARCÍA ROSEllÓ, J.; MARTÍN, A.; CELA, X., 2002: Nuevas aportaciones sobre la romanización en el territorio de Iluro (Hispania Tarraconensis), Empuréis, 52, 29-54.

GELICHI, S., 2000: L'eliminazione dei rifiuti nelle città romane del nor Italia tra antichità ed alto medioevo, X. Dupré, J. A. Remolà (eds.), Sordes urbis. La eliminación de residuos en la ciudad romana, Roma, 13-23.

GIRALT, J.; TUSET, F., 1993: Modelos de transformación del mundo urbano en el nordeste peninsular. Siglos V-XI, IV Congreso de Arqueología Medieval Española, vol. I, 37-46.

GUITART, J., 1976: Baetulo. Topografía arqueológica, urbanismo e historia. Badalona.

GUITART, J., 1993: La ciudad romana en el ámbito de Catalunya, La ciudad hispanorromana, Barcelona, 54-83.

GURT, J. Mª, 1999: Les ciutats i l'urbanisme, P. de Palol, A. Pladevall (dirs.), Del Romà al Romànic. Història, Art $i$ Cultura de la Tarraconense mediterrània entre els segles IV $i \mathrm{X}$, Barcelona, 63-76.

GURT, J. Mª ., 2000-2001: Transformaciones en el tejido de las ciudades hispanas durante la antigüedad tardía: dinámicas urbanas, Zephyrus, 53-54, 443-471.

GUSI, F., 1976: La Topografia urbanística de Iluro, MAMM, I, 35-39. 
GUTIÉRREZ, S., 1993: De la civitas a la madina: destrucción y formación de la ciudad en el sureste de Al-Andalus. Un debate arqueológico, IV Congreso de Arqueología Medieval Española, vol. I, 13-35

GUTIÉRREZ, S., 1996: La città della Spagna tra romanità e islamismo, G. P. Brogiolo (ed.). Early Medieval Towns in the Western Mediterranean (Ravello, 1994). Documenti di Archeologia 10, Mantua, 55-63.

JIMÉNEZ, M., 1996: Les necròpolis d'Iluro: estat de la qüestió i cronologia. Actes de la XII Sessió d'Estudis Mataronins. Museu Arxiu de Santa Maria, Mataró, 101-122.

LA ROCCA HUDSON, C., 1986: Dark Ages a Verona. Edilizia privata, aree aperte e strutture pubbliche in una città dell'Italia settentrionale, Arch.Medievale, XI, 31-78.

LE ROUX, P., 1985: L'Hispania et l'imperium. Réponse à G. Alföldy, Gerion, 3, 411-422.

LLOVET, J., 2000: Mataró. Dels origens de la vila a la ciutat contemporània. Mataró.

MACIAS J. Mª ., 2000: Tarraco en la Antigüedad tardía: un proceso simultáneo de transformación urbana e ideológica, Los orígenes del cristianismo en Valencia y su entorno, València, 259-271.

MARTÍ, C.; ARXÉ, J.; CERDÀ, J. A., 1982-1983: Notícia sobre les darreres actuacions a la Plaça Gran de Mataró. La intervenció de l'any 1981, Laietània, 2 3, 289-290.

MENEGHINI, R., 2003: La trasformazione dello spazio pubblico a Roma tra tarda antichità e alto medioevo, MEFRA , 115-2, 1049-1062.

MENEGHINI, R., SANTANGELI VALENZIANI, R., 1993: Sepolture intramuranee paesaggio urbano a Roma tra V e VII secolo, L. Parioli, P. Delogu (eds.). La storia economica di Roma nell'alto Medioevo alla luce dei recenti scavi archeologici, Firenze, 89-111.

MORER, J.; RIGO, A.; BARRASETAS, E., 1997: Les intervencions arqueològiques a l'autopista A-16: valoració de conjunt, Tribuna d'Arqueologia 199697, Barcelona, 66-98.

MURIALDO, G.; BONORA, E., 2001: Lo scavo dell' area abitativa contigua al muro di cinta interno (area D), T. Mannoni, G. Murialdo (eds.), S. Antonio: un insediamento fortificato nella Liguria Bizantina. Istituto Internazionale di Studi Liguri. Collezione di monografie prestoriche ed archeologiche, 12. Bordighera, 301-307.

NAVARRO, R., 1999: El territori i el món rura, P. de Palol, A. Pladevall (dirs.), Del romà al romànic. Història, art $i$ cultura de la Tarraconense mediterrània entre els segles IV $i \mathrm{X}$, Barcelona, 103-123.
NOLLA, J. M.; SAGRERA, 1995: Ciuitatis Empuritanae coemeteria. Les necròpolis tardanes de la Neápolis. Gerona.

OLESTI, O., 1995: El territori del Maresme en època republicana (s. III - I a.C.). Estudi d'Arqueomorfologia i Història. Mataró.

PADROS, P., 1985a: Baetulo. Arqueologia urbana 1975-1985. Badalona.

PADROS P., 1985b: Baetulo. Dades cronològiques i topogràfiques, El vi a l'antiguitat. Economia, producció $i$ comerç al Mediterrani occidental. I Col-loqui Internacional d'Arqueologia (Badalona, desembre 1985), Badalona, 153-160.

PADROS, P., 1999: CIUTAT DE BÈTULO, P. DE PALOL, A. PLADEVALL (dirs.), Del romà al romànic. Història, art $i$ cultura de la Tarraconense mediterrània entre els segles IV $i \mathrm{X}$, Barcelona, 89-90.

PELLICER, J. M., 1887: Estudios histórico-arqueológicos sobre Iluro, antigua ciudad de la España Tarraconense, región Layetana. Mataró.

PERA, J., 1992: L'aportació de l'excavació de Can Xammar al coneixement de l'urbanisme d'aquest sector d'Iluro, Laietània, 7, 5-34.

PERA, J., 1996-1997: La necrópolis paleocristiana d'Iesso (Guissona, La Segarra), Annals de l'Institut d'Estudis Gironins, XXXV-XXXVI, 1117 1129.

PREVOSTI, M.; CLARIANA, J.-F., 19932: Torre Llauder, Mataró. Vil.la romana. Mataró ( $1^{\mathrm{a}}$ edición, 1988).

RAMALLO, S., 1996: Aproximación al urbanismo de Carthago Nova entre los siglos IV-VII d.C., Spania. Estudis d'Antiguitat Tardana oferts en homenatge al professor Pere de Palol i Salellas. Publicacions de l'Abadia de Montserrat, 201-208.

RAMALLO, S.; RUIZ, E., 2000: Cartagena en la arqueología bizantina en Hispania: estado de la cuestión, V Reunió d'Arqueologia Cristiana Hispánica (Cartagena, 16-19 abril 1998), Barcelona, 305-322.

REMOLÀ, J. A., 2000a: Las ánforas tardo-antiguas en Tarraco (Hispania Tarraconensis). Siglos IV-VII d.C. Barcelona.

REMOLÀ, J. A., 2000b: Sobre la interpretación arqueológica de los vertederos, X. Dupré, J. A. Remolà (eds.), Sordes urbis. La eliminación de residuos en la ciudad romana, Roma, 107-127.

RIBAS, M., 1952: El poblament d'Ilduro. Estudi arqueològic i topogràfic des dels temps prehistòrics fins a la destrucció d'Iluro. Barcelona.

RIBAS, M., 1975: El Maresme en els primers segles del Cristianisme. Mataró.

RIBAS, M., 1981: Noticia sobre la muralla d'Iluro, Laietània, 1, 187-189. 
RIBAS, M., 1988²: Els orígens de Mataró. Mataró ( $1^{\text {a }}$ edición, Mataró, 1964).

RODÀ, I., 1989: Los primeros magistrados en colonias y municipios de la Hispania Citerior (al norte de Sagunto), J. González (ed.), Estudios sobre Urso. Colonia Iulia Genetiva, Sevilla, 345-355.

S.A.M.M. [Secció Arqueològica del Museu de Mataró] (1977): Carta dels vestigis arqueològics del terme municipal de Mataró, Museu Municipal de Mataró.
ULBERT, Th.; ORFILA, M., 2002: Die fruhchristliche Anlage von Son Fadrinet (Campos, Mallorca), $M M$, 43, 238-298.

VIGIL, A., 2000: Cabañas de época visigoda: evidencias arqueológicas del sur de Madrid. Tipología, elementos de datación y discusión, AEspA, 73, 223-252.

Recibido el 15-10-05 Aceptado el 6-12-05 